\title{
Cancer-Associated Fibroblasts Promote the Chemo-resistance in Gastric Cancer through Secreting IL-11 Targeting JAK/STAT3/BcI2 Pathway
}

\author{
Jun Ma, MS ${ }^{12}$ \\ Xiao Song, MS ${ }^{3}$ \\ Xiaowu $\mathrm{Xu}_{\mathrm{u}}, \mathrm{MD}^{1,2}$ \\ Yiping Mou, MD, PhD',2
}

\begin{abstract}
${ }^{1}$ Department of Gastrointestinal and Pancreatic Surgery, Zhejiang Provincial People's Hospital, People's Hospital of Hangzhou Medical College, Hangzhou, ${ }^{2}$ Key Laboratory of Gastroenterology of Zhejiang Province, Hangzhou,

${ }^{3}$ Department of General Surgery,

Ningbo No. 2 Hospital, Ningbo, China
\end{abstract}

Correspondence: Yiping Mou, MD, PhD Department of Gastrointestinal and Pancreatic Surgery, Zhejiang Provincial People's Hospital People's Hospital of Hangzhou Medical College, 158 Shangtang Road, Hangzhou, Zhejiang, China and Key Laboratory of Gastroenterology of Zhejiang Province, Hangzhou 310014, China

Tel: 86-0571-85893408

Fax: 86-0571-87091089

E-mail: yp66self@163.com

Received January 9, 2018

Accepted April 15, 2018

Published Online April 20, 2018

\begin{abstract}
Purpose
Our aim was to detect the potential role of interleukin 11 (IL-11) in the development of chemo-resistance in gastric cancer and to reveal the mechanism involved in the process.
\end{abstract}

\section{Materials and Methods}

Here, we used flow cytometry to examine the percentage of cancer-associated-fibroblasts in tumor samples from chemo-resistant and -sensitive gastric cancer patients. Using MTT assay, we detected the cell viability under different conditions. Using quantitative real-time polymerase chain reaction and Western blotting, we determined the target expressions in mRNA and protein levels. We also performed immunohistochemistry and immunofluorescence to detect the target proteins under different conditions. Animal models were constructed to verify the potential role of IL-11 in chemo-resistant develop in vivo.

\section{Results}

Herein, we observed enriched cancer associated fibroblasts in drug resistant tumor tissues from gastric patients. Those fibroblasts facilitate the chemotherapeutic drugs resistance development through the secretion of IL-11, which activates the IL-11/IL-11R/gp130/ JAK/STAT3 anti-apoptosis signaling pathway in gastric cancer cells. We found that the combination of chemotherapeutic drugs and JAK inhibitor overcomes the resistance and increases the survival of mice with gastric cancer xenografts.

\section{Conclusion}

Our results demonstrated that IL-11 contributed to the obtain of resistance to chemotherapy drugs through gp130/JAK/STAT3/Bcl2 pathway, and targeting the IL-11 signaling pathway induced by fibroblasts might be a promising strategy to overcome the multi-drugs resistant cancer in clinic.

\section{Introduction}

As the fifth most frequently diagnosed cancer worldwide, gastric cancer has become one of the major health problems worldwide. Though the development of medicine and technology has helped to improve the clinical efficacy of gastric cancer, it still ranks as the fifth cancer-related deaths in China [1]. Chemotherapy has achieved some clinical efficacy for gastric cancer treatment; however, some patients still showed

\section{Key words}

Cancer-associated fibroblasts, Stomach noplasms, Drug resistance, Interleukin-11, JAK/STAT3 no response after standard chemotherapy. One of the common reported reasons of failed chemotherapy in clinic is the development of drug resistance [2]. Unfortunately, the underlying mechanism of multi-drugs resistance development in gastric cancer is still unclear and innovative strategies are urgent to overcome the drug resistance in clinic.

Apart from sole cancer cells, tumors are also composed by other components such as endothelial cells, fibroblasts, and infiltrating immune cells, termed as tumor microenvironment. Recently, the tumor microenvironment has attracted 
increasing attention owing to its role in providing circumstance for cancer progression and metastasis [3]. Cancerassociated-fibroblasts (CAFs), a sub-population in tumor microenvironment, participate in various tumor progressions, including tumor sustained growth, enhanced cancer metastasis and so on [4]. Recent evidences suggest that the chemo-kines, cytokines and growth factors secreted by CAFs are key players to promote tumor progressions and facilitate the drug resistance development [5]. Notably, interleukin (IL)-6 cytokine family has been reported to be involved in cancer invasion and proliferation [6]. Interestingly, IL-11, as the member of IL-6 family, has been revealed to accumulate in solid tumors and worked as a key player in cancer progression and drug resistance, which could be secreted by CAFs in tumor sites [7-9]. Recent reports have also shown that IL-11 could influence tumor progressions for prolonging stem cells survival, decreasing apoptosis and promoting cell invasion in solid tumors $[9,10]$. It is remarkable that signal transducer and activator of transcription (STAT) family proteins, especially STAT3, selectively induce and maintain a procarcinogenic inflammatory microenvironment in the progress of cancer initiation and cancer progression [11]. And Zheng et al. [11] evidenced that IL-11 activated the JAK/STAT3 pathway once binding to IL-11R and gp130 activation. Given the central involvement of CAFs in cancer metastasis, there is considerable interest in its role in the development of drug resistance in gastric cancer.

The purpose of this study was to investigate the role of CAFs in gastric cancer acquiring chemo-resistance in vitro and in vivo. For this purpose, we obtained CAFs from surgical gastric cancer specimen resections and further used samples to test their influence on gastric cancer cells. Here, we observed accumulated expression of CAFs in the gastric tumor samples from chemo-resistant patients. And we convinced the role of CAFs in promoting gastric cancer cells to acquire drug resistance both in vitro and in vivo. Further, our data defined that IL-11 secreted by CAFs is the main player and the molecular basis to acquire drug resistance through JAK/STAT3/Bcl2 pathway. In addition, we demonstrated that the application of chemotherapeutic agents combined with JAK signaling inhibitor could efficiently reverse the drug resistance and it might be a potential strategy in gastric cancer treatment.
Table 1. The characteristic of gastric cancer patients

\begin{tabular}{lr} 
Age $(\mathrm{yr})$ & No. $(\%)(\mathrm{n}=\mathbf{3 0})$ \\
$\quad \geq 60$ & $18(60)$ \\
$\quad<60$ & $12(40)$ \\
Sex & \\
$\quad$ Female & $10(33)$ \\
$\quad$ Male & $20(67)$ \\
\hline Histological grade & \\
$\quad$ Well & $19(63)$ \\
\hline Poor & $11(37)$ \\
Clinical stage & \\
\hline I & $5(17)$ \\
\hline II & $9(30)$ \\
\hline III & $16(53)$ \\
Chemotherapy response & $15(50)$ \\
$\quad$ Resistance \\
$\quad$ Sensitive & $15(50)$ \\
\hline
\end{tabular}

\section{Materials and Methods}

\section{Cell lines and animals}

SGC7901 human gastric cancer cell line, BGC823 human gastric cancer cell line and BJ cells human normal fibroblast cell line were purchased from American Type Culture Collection (ATCC, Manassas, VA). All cell lines were maintained with 1640 complete medium (Gibco, Grand Island, NY) supplemented with $10 \%$ fetal calf serum (Gibco), at $37^{\circ} \mathrm{C}$ with $5 \% \mathrm{CO}_{2}$ atmosphere. Female nude mice (6-8 weeks) were purchased from Beijing HFK Bioscience (Beijing, China) and fed in SPF experimental animal rooms.

\section{Primary culture of CAFs and gastric cancer patients' sam- ples}

Primary CAFs were prepared by the outgrowth methods [12]. Primary gastric cancer tumor and adjacent normal samples were sterilely obtained after the surgery at the Zhejiang Provincial People's Hospital (Table 1). Samples were sent to the laboratory within 2 hours. According to the clinical data, samples were divided into chemo-sensitive and chemoresistant groups. The samples were minced and cultured with F12 culture medium (HyClone, Los Angeles, CA) containing type II and IV collagenase (Sigma, San Francisco, CA) to digest at $37^{\circ} \mathrm{C}, 5 \% \mathrm{CO}_{2}$ incubator for 2 hours, followed by filtration (BD Biosciences, Franklin Lakes, NJ). Then the cell precipitation was collected and seeded into 6-well plate in 2 mL F12 medium supplemented with $10 \%$ fetal bovine 
serum for 4 hours at $37^{\circ} \mathrm{C}$. Next, the medium was replaced with fresh medium to remove the un-adherent cells and the remaining cells were collected. After 2-4 passages, we sorted the CD90 positive cells [13] with BD FACSAria III to collect fibroblasts and cultured for further study.

To obtain the cultured medium of CAFs (CAFs-CM), $2 \times 10^{5}$ separated CAFs were seeded in the plates and cultured under conditioned circumstances. Twenty-four hours later, the medium was replaced by serum-free medium. Two days later, the supernatants were obtained and stored at $-80^{\circ} \mathrm{C}$ for further use.

\section{Cell viability analysis}

For the detection of CAF effect on chemotherapeutic drugs on BGC923 and SGC7901, we co-cultured CAFs $\left(10^{5}\right)$ and cancer cells $\left(5 \times 10^{4}\right)$ for 24 hours, and we removed CAFs by labeling CD90. Then BGC923 and SGC7901 were seeded, followed by adding drugs as following: cisplatin (DDP; 2, 4, 6, $8,10,12$, and $16 \mu \mathrm{g} / \mathrm{mL}$; Sigma), doxorubicin $(1,5,25,50,200$, 500 , and $800 \mu \mathrm{M}$; Sigma) or etoposide (0.01, 0.1, 1, 2, 20, 200, and $500 \mu \mathrm{M}$; Sigma) for 48 hours.

To examine the role of CAFs-CM (collected after $10^{5} \mathrm{CAFs}$ culture for 24 hours) or rhIL-11 on cancer cells resistance to chemotherapy, we pre-treated the cancer cells with CAFs$\mathrm{CM}$ or rhIL-11 $(2.5,5,10,20$, and $50 \mathrm{ng} / \mathrm{mL})$ for 24 hours, then employed $10 \mu \mathrm{g} / \mathrm{mL}$ DDP, $200 \mu \mathrm{M}$ Etoposide and $20 \mu \mathrm{M}$ doxorubicin for BGC823 cells and $8 \mu \mathrm{g} / \mathrm{mL}$ DDP, $200 \mu \mathrm{M}$ Etoposide and $200 \mu \mathrm{M}$ doxorubicin for SGC7901 cells at the presence or absence of IL-11 neutralizing antibody (25 $\mu \mathrm{g} / \mathrm{mL})$ or ruxolitinib $(5 \mu \mathrm{M})$ for 48 hours. The apoptosis of cancer cells from tumor tissues were detect by the Annexin $\mathrm{V}$ and propidum iodide (PI) apoptosis detection kit (BD Biosciences) as guided.

Under some experiments, we used STAT3, IL-11R or Bcl2 knockdown BGC823 or SGC7901 cells to examine the effect of IL-11 on cell viability when treated with chemotherapeutic agents.

All cell viability experiments were determined by MTT assay. Briefly, cells were seeded into 96-well culture plates at the density of 3,000 per well. Twelve hours later, cells were treated at the determined conditions. Cell growth was measured after addition of $10 \mu \mathrm{L}$ MTT solution $(0.5 \mathrm{mg} / \mathrm{mL}$, Solarbio, Beijing, China). After 4 hours incubation at $37^{\circ} \mathrm{C}$, the medium was replaced with $100 \mu \mathrm{L}$ dimethylsulfoxide and vortexed for 10 minutes. Absorbance was measured at $570 \mathrm{~nm}$ by a microplate reader (Bio-Rad, Hercules, CA). Each experiment was performed for at least three times.

\section{RNA interference}

siRNA targeted human STAT3 (siRNA\#1, GUGAAGU-
CAACAUGCCUGC; and siRNA\#2, GCAGGCAUGUUGACUUCAC) and siRNA targeted human BCL-2 (siRNA\#1, GCAGCAGCTGAACAACAT and SiRNA\#2, AATTAAAAAAGCAGCA) and control siRNA were purchased from RiboBio (Guanghzou, China). siRNA $(50 \mu \mathrm{M})$ was transfected to gastric cancer cells with lipofectamine RNAiMax (Invitrogen, Carlsbad, CA) as guidance. Lentivirus vector with shRNA targeting IL-11 receptor (5'-GGACCATACCAAAGGAGAT-3') and negative control were purchased from Genechem Company (Shanghai, China).

\section{Flow cytometry}

To examine the percentage of CAFs in gastric cancer patients tissues, cells were incubated with CD90 (eBioscience, San Diego, CA) for 20 minutes at room temperature, after washed twice and then re-suspended in phosphate buffered saline (PBS). Flow cytometry was performed on the BD Canto II (BD Biosciences). 7-AAD was used to exclude the dead cells. IgG (eBioscience) was used as the negative control.

To detect the effect of IL-11 on apoptosis of cancer cells when treated with chemotherapeutic agents, SGC7901 cells $\left(1 \times 10^{6}\right.$ per mouse $)$ were subcutaneous injected into the nude mice. When the tumor volume reached $5 \mathrm{~mm} \times 5 \mathrm{~mm}$, doxorubicin $(5 \mathrm{mg} / \mathrm{kg})$ monotherapy or combined with CAFs$\mathrm{CM}$, rhIL-11 $(2.5 \mu \mathrm{g} / \mathrm{kg})$, in the presence or absence of IL-11 neutralizing antibody $(25 \mu \mathrm{g} / \mathrm{mL})$ were used to treated the mice by tail intravenous injection every 2 days. PBS was used as control group. Mice were treated for 2 weeks. Then the mice were sacrificed to obtain the tumor tissues. After mincing and digesting the tumor tissues, the tissue suspension was filtered and washed by PBS, followed by staining with CD45 (eBioscience), Annexin V (eBioscience), and PI (eBioscience). Then flow cytometry was used to examine the apoptosis rate.

\section{Real-time polymerase chain reaction}

Two-microgram cDNA was performed as a template for the real-time polymerase chain reaction (PCR) analysis, with a SYBR Green Mix (Thermo Fisher, Waltham, MA) and Agilent Technologies Stratagene Mx3500P real-time PCR system. The $\Delta \Delta \mathrm{Ct}$ method was used for the relative quantification with actin as a reference. The primers used are listed as follows: human IL-11 forward primer 5'-CGAGCGGACCTACTGTCCTA- $3^{\prime}$ and reverse primer $5^{\prime}$-GCCCAGTCAAGTGTCAGGTG-3'; human SDF-1 forward primer 5'-ATTCTCAACACTCCAAACTGTGC- $3^{\prime}$ and reverse primer $5^{\prime}$-ACTTTAGCTTCGGGTCAATGC-3'; human HGF forward primer $5^{\prime}$-GCTATCGGGGTAAAGACCTACA-3' and reverse primer 5'-CGTAGCGTACCTCTGGATTGC-3'; human VEGFo 
forward primer $5^{\prime}$-AGGGCAGAATCATCACGAAGT- ${ }^{\prime}$ and reverse primer $5^{\prime}$-AGGGTCTCGATTGGATGGCA-3'; human FGF forward primer $5^{\prime}$-TGGCTATTTGGTGGGGATCAA-3' and reverse primer $5^{\prime}$-GAAGAGGGCACTTCTCACTCC-3'; human PDGF forward primer 5 '-GCAAGACCAGGACGGTCATTT- $3^{\prime}$ and reverse primer $5^{\prime}$-GGCACTTGACACTGCTCGT-3'; human IL-11R forward primer 5'-CTGGGCTAGGGCATGAACTG-3' and reverse primer $5^{\prime}$-CTGGGACTCCAAGTGCAAGA-3'; human SDF-1R forward primer $5^{\prime}$-ACTACACCGAGGAAATGGGCT-3' and reverse primer $5^{\prime}$-CCCACAATGCCAGTTAAGAAGA-3'; human VEFGR forward primer $5^{\prime}$-AGGGCAGAATCATCACGAAGT- $3^{\prime}$ and reverse primer 5'-AGGGTCTCGATTGGATGGCA-3'; human HGFR forward primer $5^{\prime}$-AGCAATGGGGAGTGTAAAGAGG-3' and reverse primer $5^{\prime}$-CCCAGTCTTGTACTCAGCAAC-3'; human PDGFR forward primer 5'-TGGCAGTACCCCATGTCTGAA- ${ }^{\prime}$ and reverse primer $5^{\prime}$-CCAAGACCGTCACAAAAAGGC-3'; human FGFR forward primer $5^{\prime}$-ACTAC-

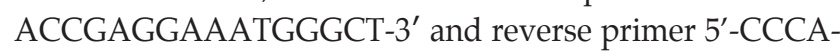
CAATGCCAGTTAAGAAGA-3'; human GAPDH forward primer 5'-GGAGCGAGATCCCTCCAAAAT-3', reverse primer 5'-GGCTGTTGTCATACTTCTCATGG-3'. The expressions of IL-1 F9 (Hs00219742_m1) and IL-1 F9R (Hs00213600_m1) were detected by using TaqMan primer sets (Applied Biosystems, Foster City, CA) [14].

\section{Enzyme-linked immunosorbent assay}

Cancer associated fibroblasts or BJ cells were seeded at the density of $5 \times 10^{5}$ cells per well. Forty-eight hours later, the cells were washed twice with PBS and incubated with $2 \mathrm{~mL}$ serum-free Dulbecco's modified Eagle's medium for 24 hours. Then the supernatants were collected and stored at $-80^{\circ} \mathrm{C}$ for further use. The levels of IL- 11 in the CM were examined by using enzyme-linked immunosorbent assay kits (R\&D Systems Inc., Minneapolis, MN), according to the manufacturer's recommended protocol. Each experiment was performed in triplicate.

\section{Western blotting}

Whole cell lysates were prepared from BGC823 or SGC7901 cells treated as previous designed and separated by sodium dodecyl sulfate polyacrylamide gel electrophoresis at $100 \mathrm{~V}$ for 1 hour. Next, the separated proteins were transferred to NC membranes (Millipore, Billerica, MA). The samples were blocked with $5 \%$ bovine serum albumin (BSA) in TBS containing $0.1 \%$ Tween-20 for 1 hour at room temperature and incubated overnight at $4^{\circ} \mathrm{C}$ with one of the following antibodies: JAK (1:200, Abcam, Cambridge, UK), phospho JAK (Ser473) (1:200, Abcam), STAT3 (1:300, Abcam), phospho STAT3 (Tyr705) (1:300, Abcam), BCL-2 (1:200, Abcam),
GP130 (1:300, Abcam) and actin (1:500, Abcam). The samples were washed with TBST and incubated with HRP-conjugated secondary antibodies for 1 hour at room temperature. Proteins were visualized by ECL western blotting reagent (Thermo Fisher).

\section{Immunofluorescence staining}

Tumor tissues were kept in 4\% paraformaldehyde overnight, then processed, embedded in paraffin, and sectioned at $4 \mu \mathrm{m}$ for further study. To detect the expression of JAK and STAT3 in gastric cancer tissues, antigen retrieval was done using citric acid and sodium citrate in a Microwave oven (Media, Guangdong, China). Then the sections or gastric cancer cells (fixed with $4 \%$ paraformaldehyde and permeabilized with $0.3 \%$ Triton X-100) were blocked with 5\% BSA in PBS and incubated with p-JAK (1:200, Abcam) or p-STAT3 (1:500, Abcam) at $4^{\circ} \mathrm{C}$ overnight, followed by secondary antibodies (Thermo Fisher) for 1 hour at room temperature. Nuclei were stained with the DAPI solution (1 $\mu \mathrm{g} / \mathrm{mL}$ ). Confocal microscope (Olympus, Tokyo, Japan) was used to visualize the sections.

\section{Immunohistochemistry}

The sections of tumors were incubated with IL-11 (1:500, Abcam), IL-11 receptor (1:500, Abcam) or $\alpha$-smooth muscle actin ( $\alpha$-SMA; 1:500, Abcam) at $4^{\circ} \mathrm{C}$ overnight, followed by signal amplification using an ABC HRP Kit (Thermo Fisher) and counter-staining with hematoxylin, dehydration with series of graded ethanol and cleaned with xylene. Microscope (Leica, Oskar-Barnack, Germany) was used to visualize the sections.

\section{TUNEL detection assay}

To test cell death and proliferation in patients' samples, the sections of tumors were incubated with the mixture of terminal deoxynucleotidyl transferase, nucleotide, and reaction buffer as indicated by TUNEL Cell Death Detection Kit (Roche, Basel, Switzerland). Apoptosis percentage was calculated by percent of tumor cells with positive staining.

\section{Animal protocols}

To evaluate the anticancer effects of ruxolitinib combined with chemotherapeutic agents, SGC7901 cells $\left(1 \times 10^{6}\right.$ per mouse) were subcutaneous injected into the nude mice. When the tumor volume reached $5 \mathrm{~mm} \times 5 \mathrm{~mm}$, PBS, ruxolitinib $(10 \mathrm{mg} / \mathrm{kg})$, DDP $(5 \mathrm{mg} / \mathrm{kg})$, doxorubicin $(5 \mathrm{mg} / \mathrm{kg})$, etoposide $(10 \mathrm{mg} / \mathrm{kg})$, and ruxolitinib $(10 \mathrm{mg} / \mathrm{kg})$ combined with doxorubicin $(5 \mathrm{mg} / \mathrm{kg})$, DDP $(5 \mathrm{mg} / \mathrm{kg})$, etoposide (10 


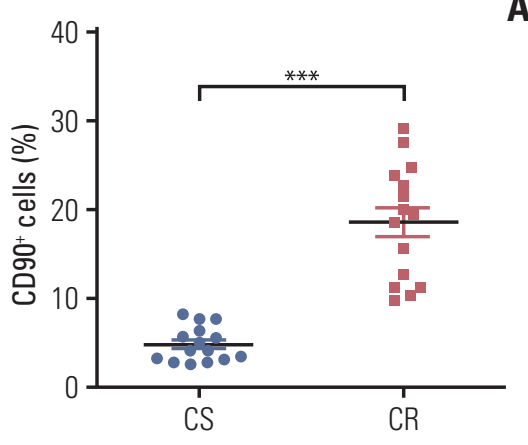

CS

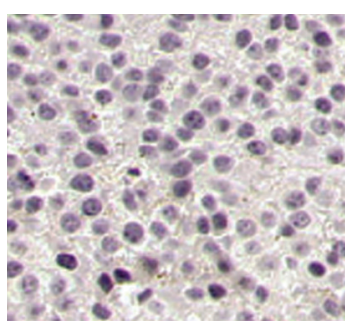

CR

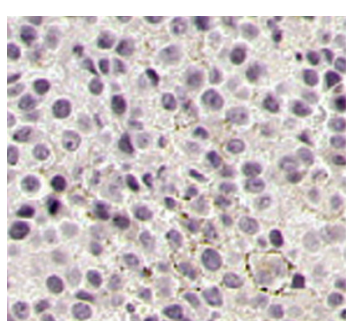

C

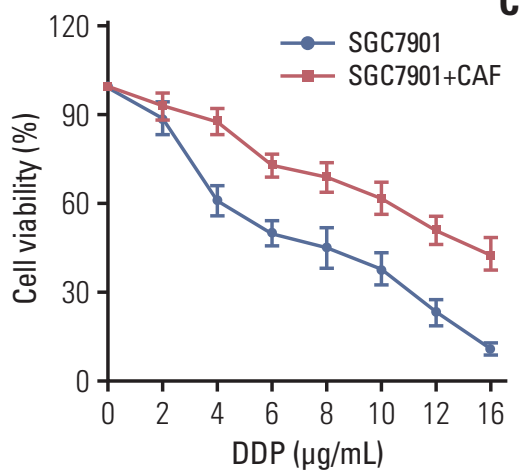

$\mathbf{F}$

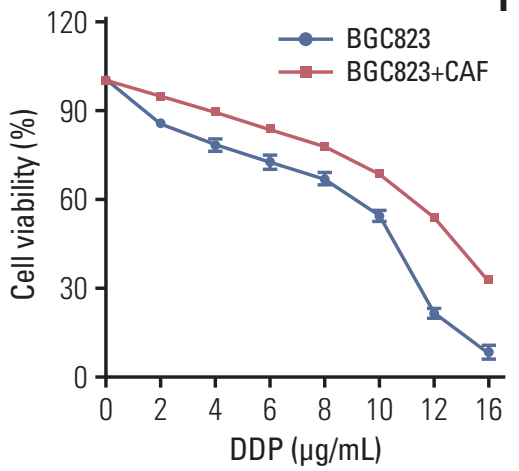

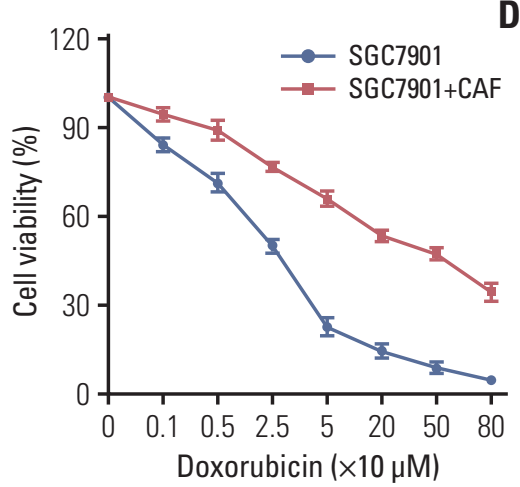

G

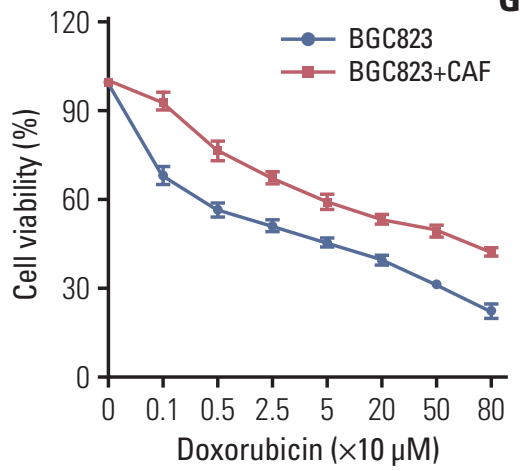

E

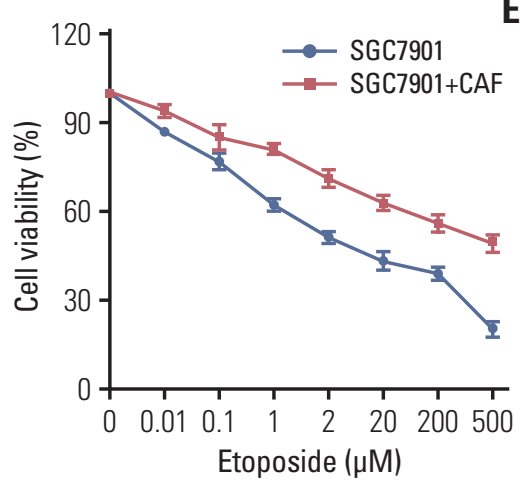

Fig. 1. Enriched cancer-associated-fibroblasts (CAFs) enhanced the resistance of gastric cancer cells to chemotherapy. Accumulated CAFs in the chemotherapy-resistant gastric tumor sites and facilitate the resistance to chemotherapy drugs in gastric cancer cells. (A) The percentage of the cancer-associated fibroblasts in samples from chemo-sensitive (CS) and chemo-resistance (CR) gastric cancer patients was detected by flow cytometry. (B) The expression of the cancer-associated fibroblasts in samples from CS and CR gastric cancer patients was detected by immunohistochemistry. (C-H) The cell viability of SGC7901was detected after treated by different concentration of DDP (C), doxorubicin (D), and etoposide (E) pre-co-cultured with or without CAFs by using MTT assay. The cell viability of BGC823 was detected after treated by different concentration of DDP (F), doxorubicin (G), and etoposide (H) pre-co-cultured with or without CAFs by using MTT assay. The data was presented as mean \pm standard error of mean from three independent experiments. ${ }^{* * *} \mathrm{p}<0.001$. 
$\mathrm{mg} / \mathrm{kg}$ ) were used to treated the mice by tail intravenous injection every 2 days. Mice were treated for 3 weeks. To establish drug resistant animal models, SGC7901 cells $\left(1 \times 10^{6}\right.$ per mouse) were subcutaneous injected into the nude mice. When the tumor volume reached $5 \mathrm{~mm} \times 5 \mathrm{~mm}$, $50 \mathrm{ng}$ IL-11 was injected into the mice by intratumor injection. After 4 days, PBS, ruxolitinib (10 mg/ $\mathrm{kg})$, DPP $(5 \mathrm{mg} / \mathrm{kg})$, doxorubicin $(5 \mathrm{mg} / \mathrm{kg})$, etoposide $(10 \mathrm{mg} / \mathrm{kg})$, and ruxolitinib (10 $\mathrm{mg} / \mathrm{kg}$ ) combined with doxorubicin $(5 \mathrm{mg} / \mathrm{kg}$ ), DPP (5 $\mathrm{mg} / \mathrm{kg})$, etoposide $(10 \mathrm{mg} / \mathrm{kg}$ ) were used to treated the mice by tail intravenous injection every 2 days. Mice were treated for 3 weeks. Tumor growth was recorded with the length $(\mathrm{L})$ and width $(\mathrm{W})$ of tumors by vernier calipers, and the tumor volume $(\mathrm{V})$ was calculated by the formula $\mathrm{V}=\left(\mathrm{L} \times \mathrm{W}^{2}\right) / 2$. The data was monitored every 2 days and the survival of tumor bearing-mice was observed every day.

\section{Statistical analysis}

Results were presented as mean \pm standard error of mean and statistical significance was examined by an unpaired Student's $t$ test by the Graphpad 6.0 software (San Diego, CA). Survival analysis was performed by Kaplan-Meier method and evaluated using the log-rank test. p-value of $<0.05$ was considered as statistically significant.

\section{Ethical statement}

All studies were approved by the animal care and used committee of laboratory animal monitoring of People's Hospital of Hangzhou Medical College. All the animal experiments were approved by the IACUC in People's Hospital of Hangzhou Medical College.

\section{Results}

\section{Enriched CAFs enhanced the resistance of gastric cancer cells to chemotherapy}

The tumor stroma consists of various elements including $\mathrm{CAFs}$, macrophages, lymphocytes and extracellular matrix, which are involved in the tumor initiation, metastasis, acquiring drug resistance and so forth $[15,16]$. Among these, CAFs is reported as an important component to mediate drug resistance $[17,18]$. To assess the expression landscape of CAFs in gastric cancer, we isolated fibroblasts from clinical gastric cancer patients' samples resistant or sensitive to chemotherapy, and the CAFs are labeled as $\mathrm{CD} 90^{+}$by flow cytometry. We found that the percentage of CAFs in samples from chemo-resistant tissues was significantly higher compared with samples from chemo-sensitive tissues (Fig. 1A). The higher expression of CAFs in chemo-resistant tissues was also verified using $\alpha$-SMA (Fig. 1B). These data indicated that the enriched CAFs may be involved in the process of gastric cancer cells chemo-resistance development. Herein, we isolated the CAFs from the tumor tissues and treated gastric cancer cell lines, BGC823 and SGC7901, with clinical chemotherapeutic agents (doxorubicin, DDP, and etoposide) after co-culture with or without those CAFs. We observed that the gastric cancer cells were more resistant to chemotherapeutic drugs in the CAFs co-culture conditions compared to monoculture (Fig. 1C-H). These data suggested that CAFs in gastric tumor sites result in the cancer cells drugs resistance development.

\section{CAFs regulated chemo-resistance via the secretion of IL-11}

Current thinking suggests that CAFs are capable of remodeling the surrounding cells through secreting soluble factors $[5,19]$. In line with this concept, we added the conditioned medium from CAFs to the gastric cancer cells followed by chemotherapeutic drugs treatment respectively. And we observed enhanced drug resistance in BGC823 cells treated with the CAFs-CM compared with control monoculture (Fig. 2A). Similar results were obtained when tested with SGC7901 (Fig. 2B), indicating that CAFs mediated chemoresistance of gastric cancer cells through soluble factors. To further investigate the exact cytokines of CAFs-induced resistance, we screened the expressions of major cytokines (IL-11, stromal cell-derived factor-1, hepatocyte growth factor, fibroblast growth factor, platelet-derived growth factor, vascular endothelial growth factor, and IL-1 F9) by CAFs and normal fibroblasts. And we observed that the expression of IL-11 was significantly higher in CAFs than that from normal samples (nearly 90-fold), while no significant different expression of the other cytokines was observed (Fig. 2C and D). Correspondingly, the IL-11 receptor had higher expression in SGC7901 cells co-cultured with CAFs-CM compared with monoculture (Fig. 2E). Based on these data, we hypothesized that IL-11 may work as a key player to mediate drug resistance in gastric cancer cells. So, we applied gradient recombinant human IL-11 to pre-treat BGC823 and SGC7901 cells followed by chemo-therapeutic drugs treatment. We found that rhIL-11 significantly enhanced the drug resistance in a dose dependent manner (S1A and S1B Fig.). To further verify this, we treated BGC823 cells with CAFs-CM or recombinant human IL-11 in the presence or absence of IL-11 neutralizing antibody. In line with our hypothesis, BGC823 cells treated with IL-11 or CAFs-CM showed enhanced drug resistance while the addition of IL-11 neutralizing antibody in CAFs- 

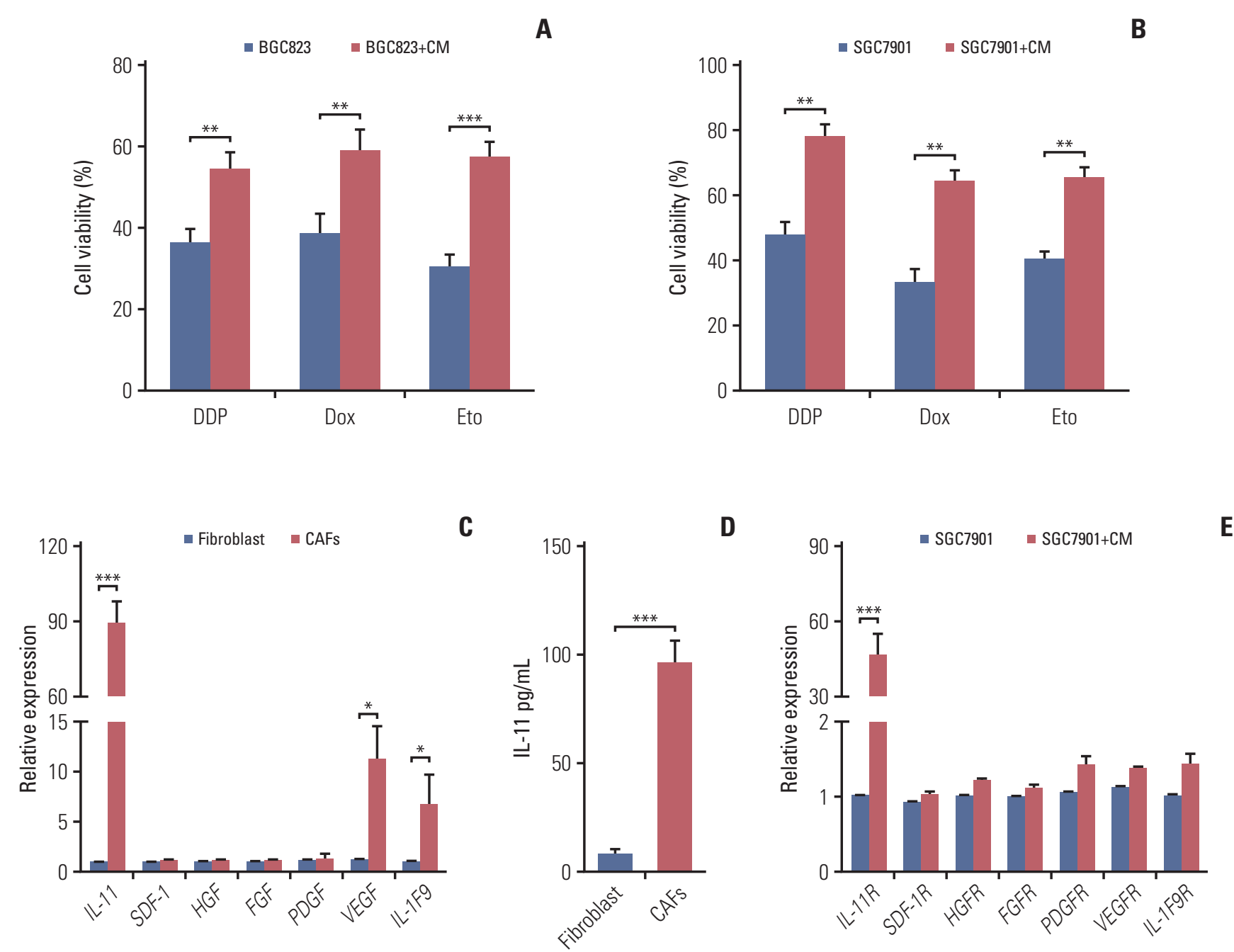

Fig. 2. Cancer-associated-fibroblasts (CAFs) regulated chemo-resistance through secreting interleukin 11 (IL-11). The effect of CAFs on the sensitivity of gastric cancer cells to chemotherapy drugs was examined by using MTT assay. (A) The cell viability of BGC823 cells treated with $10 \mu \mathrm{g} / \mathrm{mL}$ DDP, $200 \mu \mathrm{M}$ etoposide, and $20 \mu \mathrm{M}$ doxorubicin, respectively with or without CAFs medium (CM) pretreated. Dox, doxorubicin; Eto, etoposide. (B) The cell viability of SGC7901 cells treated with $8 \mu \mathrm{g} / \mathrm{mL}$ DDP, $200 \mu \mathrm{M}$ etoposide, and $20 \mu \mathrm{M}$ doxorubicin. respectively with or without CM pretreated. (C) The mRNA expression of IL-11, SDF-1, HGF, FGF, PDGF, VEGF, and IL-1F9 in normal fibroblast and CAFs. (D) The expression of IL-11R in normal fibroblast and CAFs was detected by using enzyme-linked immunosorbent assay. (E) The mRNA expression of IL-11R, VEGFR, PDGFR, HGFR, CXCR4, SDF-1R, and IL-1F9R in SGC7901 cells with or without CAFs co-cultured. (Continued to the next page)

$\mathrm{CM}$ reversed the acquired drug resistance in gastric cancer cells (Fig. 2F). And testing SGC7901 cells achieved parallel results (Fig. 2G). While knocking down IL-11 receptor reversed the drug resistance (S1C and S1D Fig.). To further demonstrate the acquired drug resistance of gastric cancer cells induced by the IL-11, we injected CAFs-CM, recombinant human IL-11, CAFs-CM combined with IL-11 neutralizing antibody into the gastric tumor-bearing mice. Then we treated the mice with doxorubicin by tail vein injection.
Interestingly, we observed that co-injecting with CAFs-CM or rhIL-11 remarkably suppressed the doxorubicin efficacy to inhibit tumor volume, while addition of IL-11 neutralizing antibody in CAFs-CM reversed the drug resistance (Fig. 2H). In consistent, combining doxorubicin with IL-11 neutralizing antibody prolonged the survival time of mice (Fig. 2I), which is in line with our results in vitro. Together, these data suggested that IL-11 secreted by CAFs is involved in the gastric cancer cells to acquire chemo-resistance. Moreover, we 

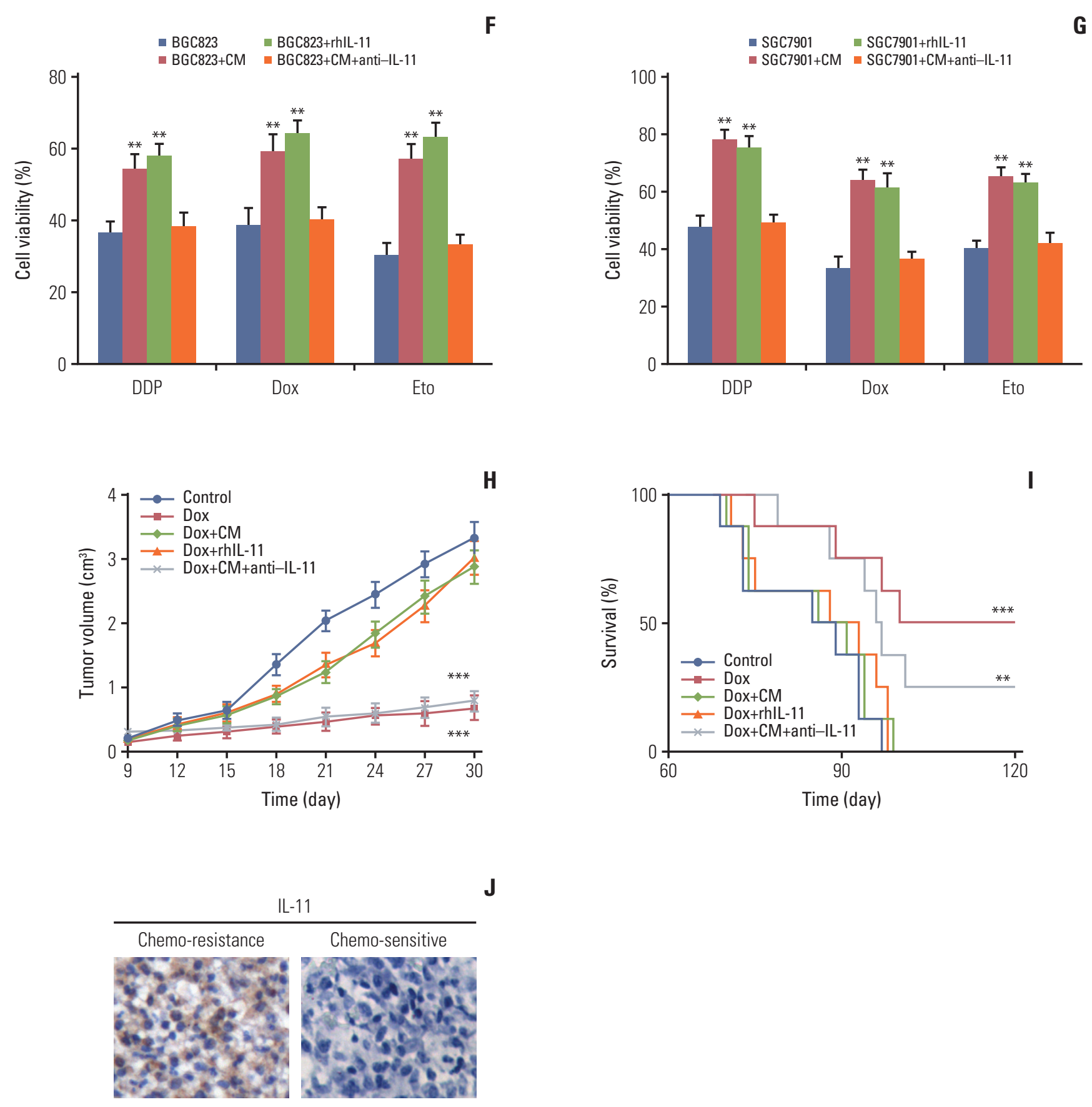

Fig. 2. (Continued from the previous page) (F) The cell viability of BGC 823 cells treated with $10 \mu \mathrm{g} / \mathrm{mL}$ DDP, $200 \mu \mathrm{M}$ etoposide, and $20 \mu \mathrm{M}$ doxorubicin, respectively with or without CAFs or rhIL-11 $(10 \mathrm{ng} / \mathrm{mL})$ pre-co-cultured in the presence or absence of IL-11 neutralizing antibody ( $25 \mu \mathrm{g} / \mathrm{mL}$ ). (G) The cell viability of SGC7901 cells treated with $8 \mu \mathrm{g} / \mathrm{mL}$ DDP, $200 \mu \mathrm{M}$ etoposide, and $200 \mu \mathrm{M}$ doxorubicin, respectively with or without CAFs or rhIL-11 $(10 \mathrm{ng} / \mathrm{mL})$ pre-co-cultured in the presence or absence of IL-11 neutralizing antibody $(25 \mu \mathrm{g} / \mathrm{mL})$. (H) The tumor volume of NOD-SCID mice bearing SGC7901 cells co-injected with CAFs-CM $(50 \mu \mathrm{L} 10 \times \mathrm{CM})$ or IL-11 $(2.5 \mu \mathrm{g} / \mathrm{kg})$ treated by doxorubicin in the presence or absence of IL-11 neutralizing antibody $(0.05 \mathrm{mg} / \mathrm{kg})$. (I) The survival curve of NOD-SCID mice bearing SGC7901 cells co-injected with CAFs$\mathrm{CM}(50 \mu \mathrm{L} 10 \times \mathrm{CM})$ or IL-11 treated by doxorubicin in the presence or absence of IL-11 neutralizing antibody $(0.05 \mathrm{mg} / \mathrm{kg})$. (J) Expression of IL-11 in gastric cancer tissues from chemo-sensitive and chemo-resistant patients. The data was presented as the mean \pm standard error of mean from three independent experiments. ${ }^{*} \mathrm{p}<0.05,{ }^{* *} \mathrm{p}<0.01,{ }^{* * *} \mathrm{p}<0.001$. 


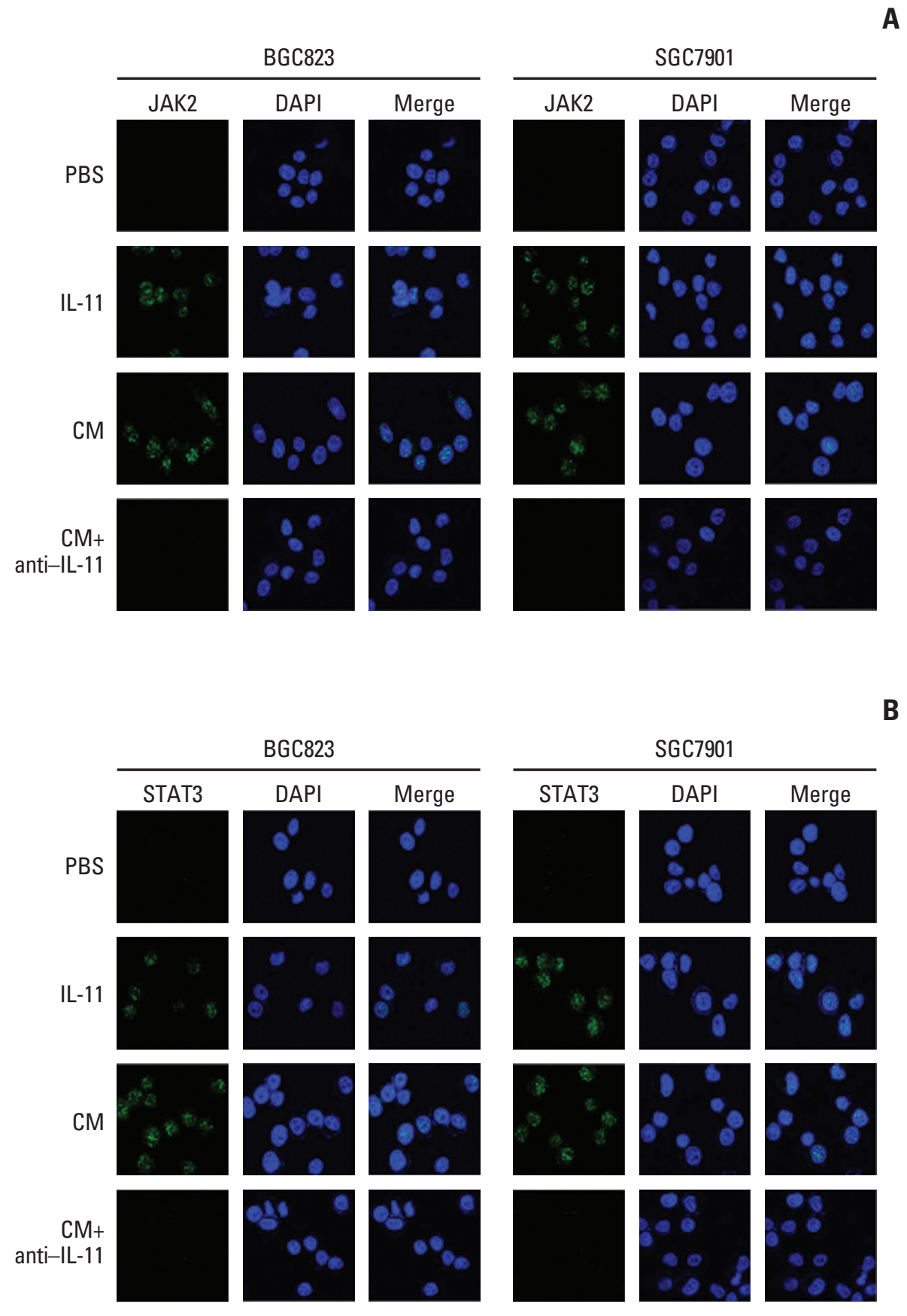

Fig. 3. Interleukin 11 (IL-11)/IL-11R signaling pathway induced the chemo-resistance through JAK/STAT3 pathway. (A) Immunofluoresence of p-JAK2 in BGC823 and SGC7901 cells pre-treated with or without cultured medium of cancer-associated-fibroblasts (CAFs-CM)/ rhIL-11 in the presence or absence of IL-11 neutralizing antibody. (B) Immunofluoresence of p-STAT3 in BGC823 and SGC7901 cells pre-treated with or without CAFs-CM/rhIL-11 $(10 \mathrm{ng} / \mathrm{mL})$ in the presence or absence of IL-11 neutralizing antibody $(25 \mu \mathrm{g} / \mathrm{mL})$. (Continued to the next page) 
C

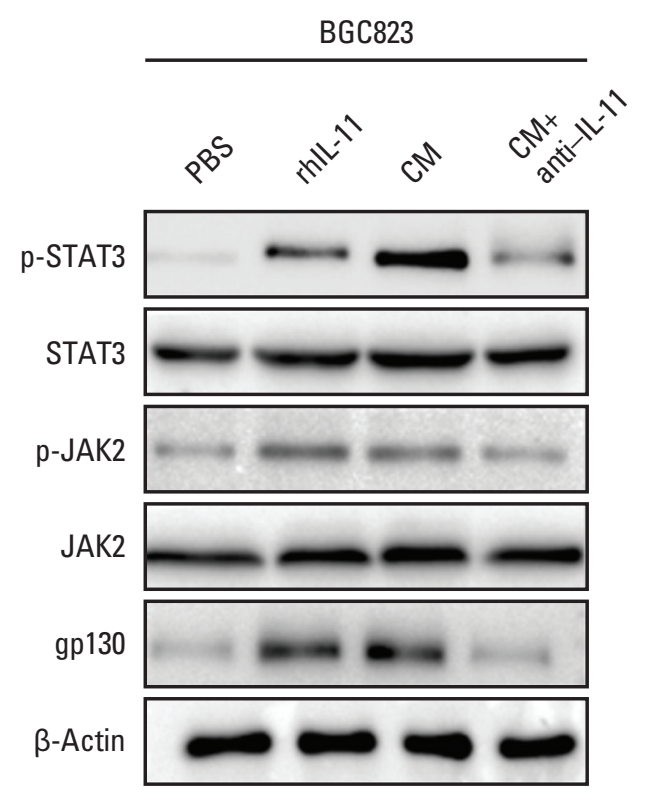

$\mathbf{E}$

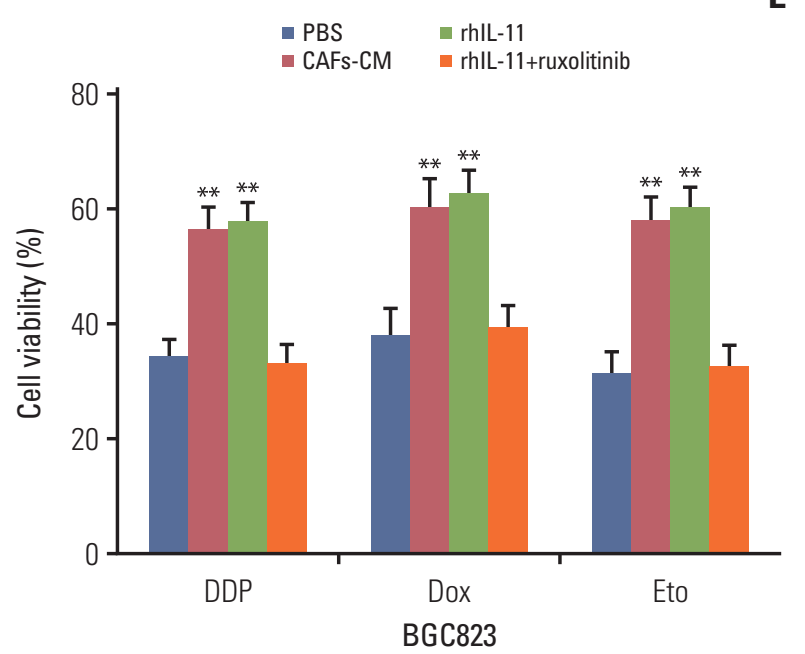

D

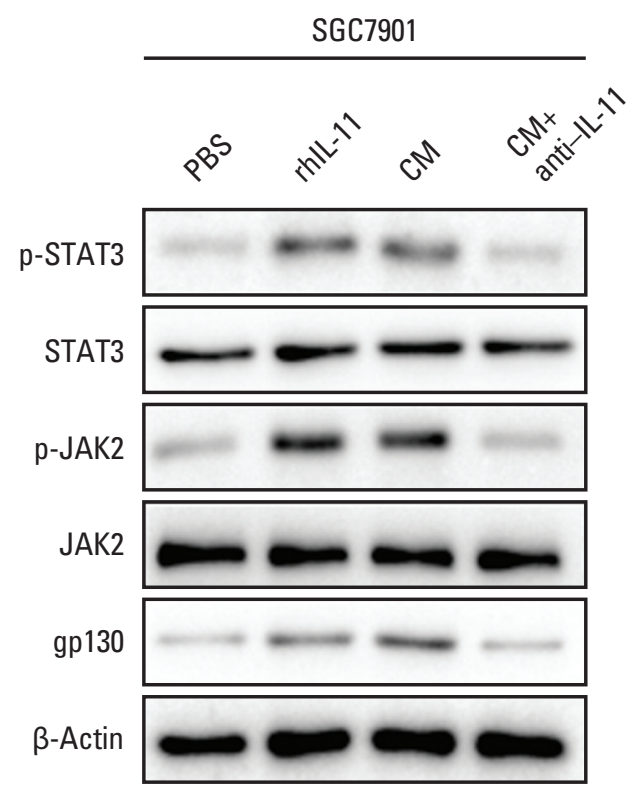

$\mathbf{F}$

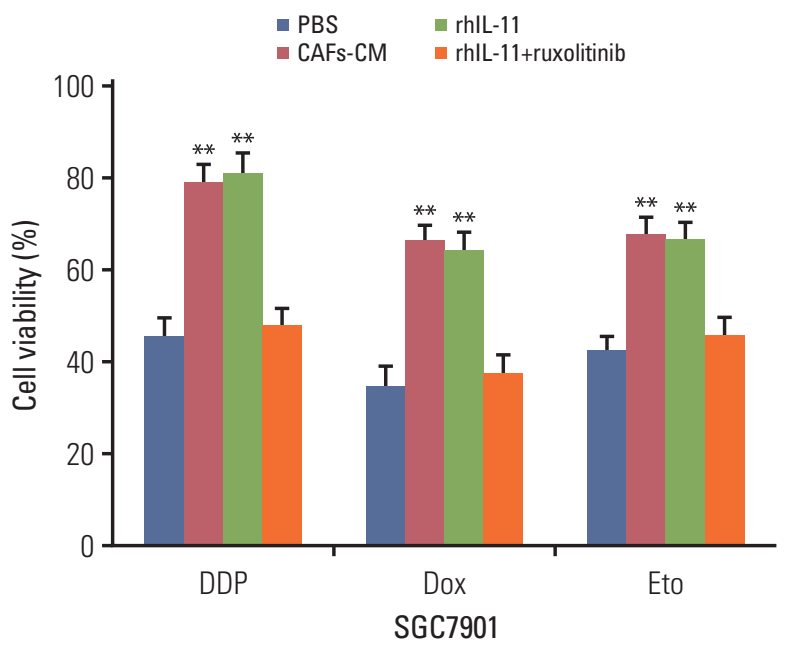

Fig. 3. (Continued from the previous page) (C) Western blotting of p-JAK2, total JAK2 and $\beta$-actin in BGC823 and SGC7901 cells pre-treated with or without CAFs-CM/rhIL-11 $(10 \mathrm{ng} / \mathrm{mL})$ in the presence or absence of IL-11 neutralizing antibody $(25 \mu \mathrm{g} / \mathrm{mL})$. (D) Western blotting of p-STAT3, total STAT3, and $\beta$-actin in BGC823 and SGC7901 cells pre-treated with or without CAFs-CM/rhIL-11 $(10 \mathrm{ng} / \mathrm{mL})$ in the presence or absence of IL-11 neutralizing antibody $(25 \mu \mathrm{g} / \mathrm{mL})$. (E) The cell viability of BGC823 cells treated with $6 \mu \mathrm{g} / \mathrm{mL}$ DDP, $6 \mu \mathrm{M}$ etoposide, and $6 \mu \mathrm{M}$ doxorubicin respectively with or without CAFs-CM or rhIL-11 $(10 \mathrm{ng} / \mathrm{mL})$ pre-co-cultured in the presence or absence of ruxolitinib $(5 \mu \mathrm{M})$. PBS, phosphate buffered saline; Dox, doxorubicin; Eto, etoposide. (F) The cell viability of SGC7901 cells treated with $4 \mu \mathrm{g} / \mathrm{mL}$ DDP, $6 \mu$ M etoposide, and $6 \mu \mathrm{M}$ doxorubicin respectively with or without CAFs-CM or rhIL-11 $(10 \mathrm{ng} / \mathrm{mL})$ pre-co-cultured in the presence or absence of ruxolitinib $(5 \mu \mathrm{M})$. (Continued to the next page) 

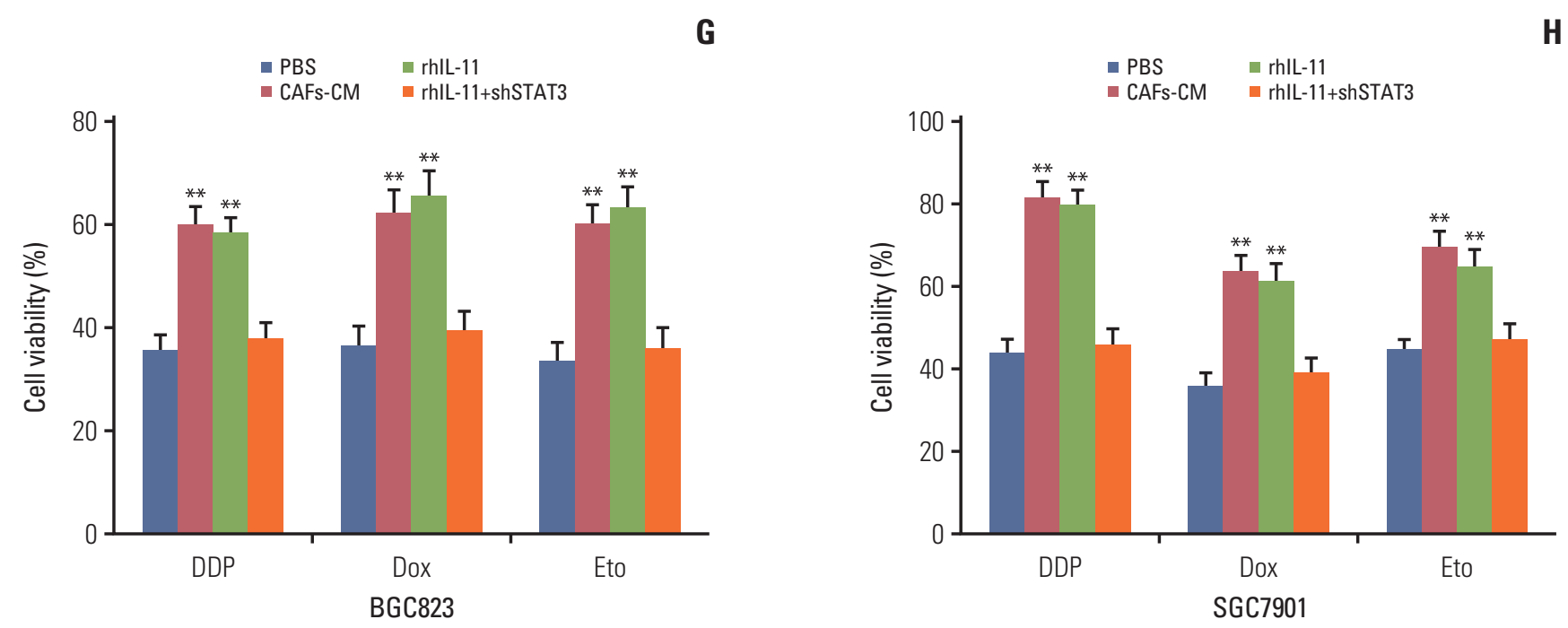

Fig. 3. (Continued from the previous page) (G) The cell viability of BGC 823 cells treated with $6 \mu \mathrm{g} / \mathrm{mL}$ DDP, $6 \mu$ M etoposide, and $6 \mu \mathrm{M}$ doxorubicin respectively with or without CAFs-CM or rhIL-11 $(10 \mathrm{ng} / \mathrm{mL})$ pre-co-cultured in the wild type or shSTAT3 cells. (H) The cell viability of SGC7901 cells treated with $4 \mu \mathrm{g} / \mathrm{mL}$ DDP, $6 \mu \mathrm{M}$ etoposide, and $6 \mu \mathrm{M}$ doxorubicin respectively with or without CAFs-CM or rhIL-11 $(10 \mathrm{ng} / \mathrm{mL})$ pre-co-cultured in the wild type or shSTAT3 cells. The data was presented as the mean \pm standard error of mean from three independent experiments. ${ }^{* *} \mathrm{p}<0.01$.

observed enhanced IL-11 and IL-11 receptor expression in tumor tissues from chemo-resistant gastric patients compared to the samples from chemo-sensitive gastric patients (Fig. 2J and S1E Fig.). And the expression of IL-11 and IL-11R expression has no influence to the cell survival or apoptosis in tumor tissues (S1F and S1G Fig.). Above data reminded us that accumulated CAFs participate in the drug resistance of gastric cancer cells through the secretion of IL-11.

\section{IL-11/IL-11R signaling pathway induced the chemo- resistance through JAK/STAT3 pathway}

In tumor microenvironment, cytokines are often characterized as functional redundancy and tissue-specific activities $[20,21]$. Current studies have shown that over-activated IL-11 contributed to the activation of the gp130 through binding to its receptor in solid tumors $[6,11]$, which afterwards activated JAK/STAT3 pathway that was involved in regulating angiogenesis, metastasis, resistance to apoptosis, cell proliferation, and immune evasion [22]. Herein, we supposed that IL-11 might participate in the drug resistance development through the activation of JAK/STAT3 pathways. So we detected the p-JAK and p-STAT3 expression in BGC823 and SGC7901 cells treated with CAFs-CM, rhIL-11, and CAFs-CM combined with IL-11 neutralizing antibody. Increased expression of p-JAK and p-STAT3 was observed in cells treated with CAFs-CM or rhIL-11 while the addition of IL-11 neutralizing antibody in CAFs-CM reversed the phe- nomenon in both BGC823 and SGC7901 cells (Fig. 3A and B), indicating that IL-11 might activate the JAK/STAT3 pathway in gastric cancer cells. To further expound the signaling pathway induced by IL-11, we detect the expression of GP130, JAK, and STAT3 by western blotting and found the activation of GP130/JAK/STAT3 signaling pathway under the condition of CAFs-CM or rhIL-11 treatment, while adding IL-11 neutralizing antibody reversed the phenomenon in both BGC823 and SGC7901 cells (Fig. 3C and D).

As phosphoraltion of JAK/STAT3 reflects the active form, these data suggested that JAK/STAT3 signaling may be a key player in the IL-11 induced drug resistance. In support of this idea, JAK inhibitor (ruxolitinib) or shSTAT3 was used to detect the acquired drug resistance maintain induced by the IL-11. And we found that the inhibition of JAK or knockdown of STAT3 reversed the drug resistance induced by IL-11 co-culture in both BGC823 and SGC7901 cells when treated with DDP, doxorubicin, and etoposide (Fig. 3E-H). Collectively, these results reminded us that the JAK/STAT3 signaling pathway activation may work as an important player in IL-11/IL-11R axis induced drug resistance in gastric cancer cells.

\section{IL-11 triggers the JAK/STAT3 pathway to elevate $\mathrm{Bcl} 2$ expression}

A diverse range of molecular mechanisms have been implicated in drug resistance, including cancer cells dor- 

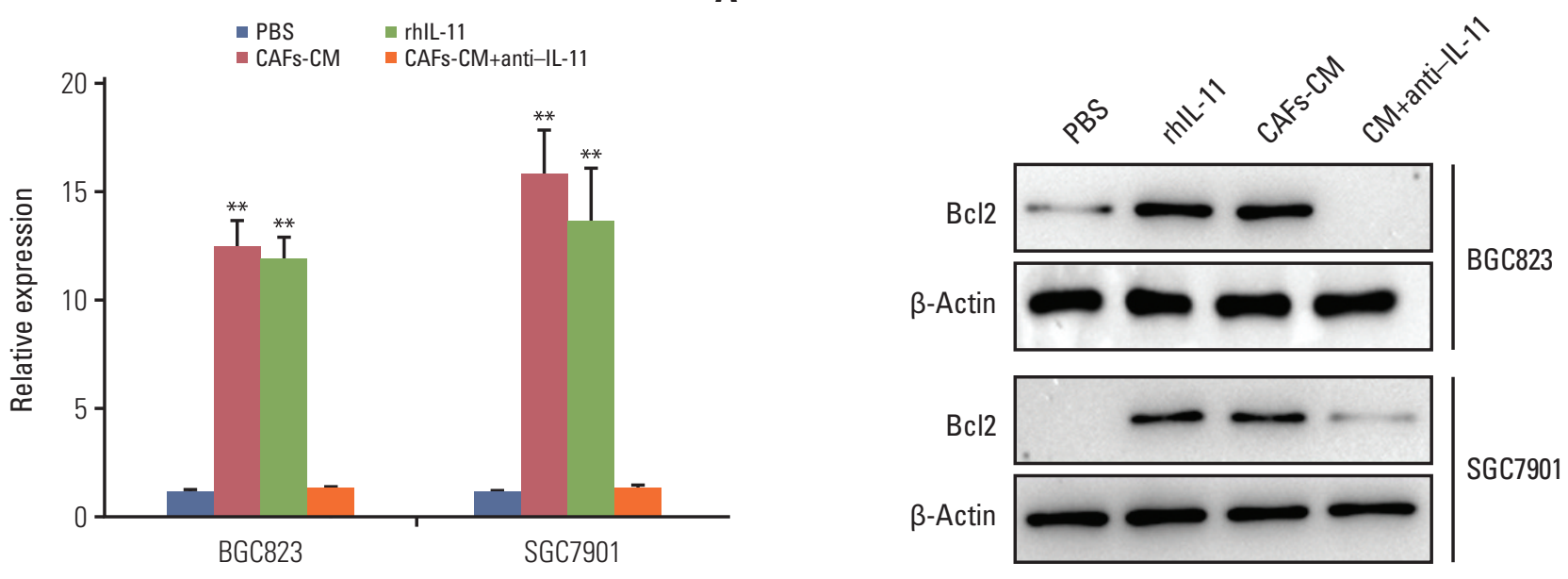

\section{C}
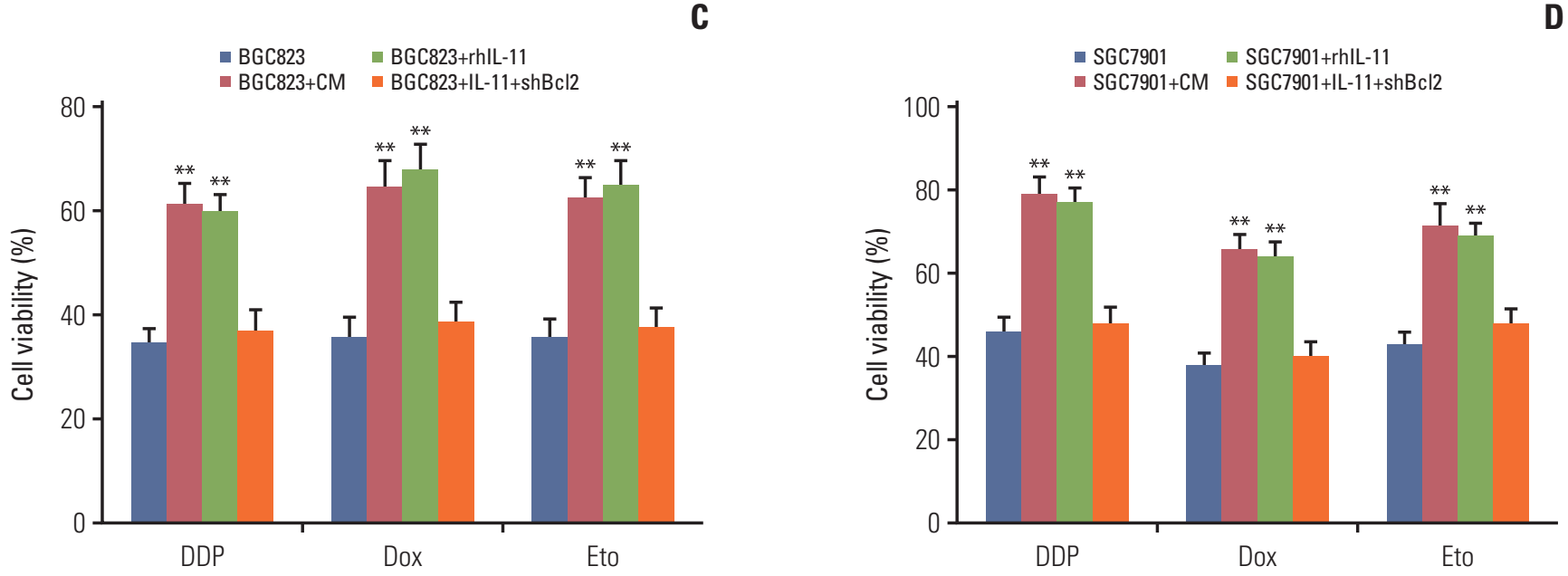

Fig. 4. Interleukin 11 (IL-11) triggers the JAK/STAT3 pathway to elevate Bcl2 expression. (A) The expression of Bcl2 in BGC823 and SGC7901 cells treated with cultured medium of cancer-associated-fibroblasts (CAFs-CM) or rhIL-11 in the presence or absence of ruxolitinib $(5 \mu \mathrm{M})$ in mRNA level. (B) The expression of Bcl2 in BGC823 and SGC7901 cells treated with CAFs-CM or rhIL-11 (10 ng/mL) in the presence or absence of ruxolitinib $(5 \mu \mathrm{M})$ in protein level. (C) The cell viability of BGC823 cells treated with CAFs-CM or rhIL-11 in wild type or Bc12 silenced cells. (D) The cell viability of SGC7901 cells treated with CAFs-CM or rhIL-11 in wild type or Bcl2 silenced cells. PBS, phosphate buffered saline; Dox, doxorubicin; Eto, etoposide. The data was presented as the mean \pm standard error of mean from three independent experiments. ${ }^{* *} \mathrm{p}<0.01$.

mancy, genes damage repair, overexpression of multi-drugs resistant proteins and so on. Anti-apoptotic family members have also been identified as a central regulator in cancer drug resistance development $[23,24]$. Among anti-apoptosis proteins family, Bcl2 plays an important role in cell anti-apoptosis activities and is overexpressed in various malignant tumors. To determine whether $\mathrm{Bcl} 2$ participate in the drugs resistance development in gastric cancer cells induced by IL-11, we treated BGC823 and SGC7901 cells with CAFs-CM or rhIL-11 and we found the expression of Bcl2 was significantly higher in the presence of CAF-CM and rhIL-11 in both mRNA and protein levels. And addition of IL-11 neutralizing antibody in CAFs-CM results in the down-regulation of $\mathrm{Bcl} 2$ respectively (Fig. 4A and $\mathrm{B}$ ), suggesting that $\mathrm{Bcl} 2$ may be involved in the drug resistance induced by IL-11 in gastric cancer. For this, we used the siRNA to knocked down the expression of $\mathrm{Bcl} 2$ and detect the drug resistance in gastric cancer cells treated with CAFs-CM or rhIL-11. CAFs-CM or 

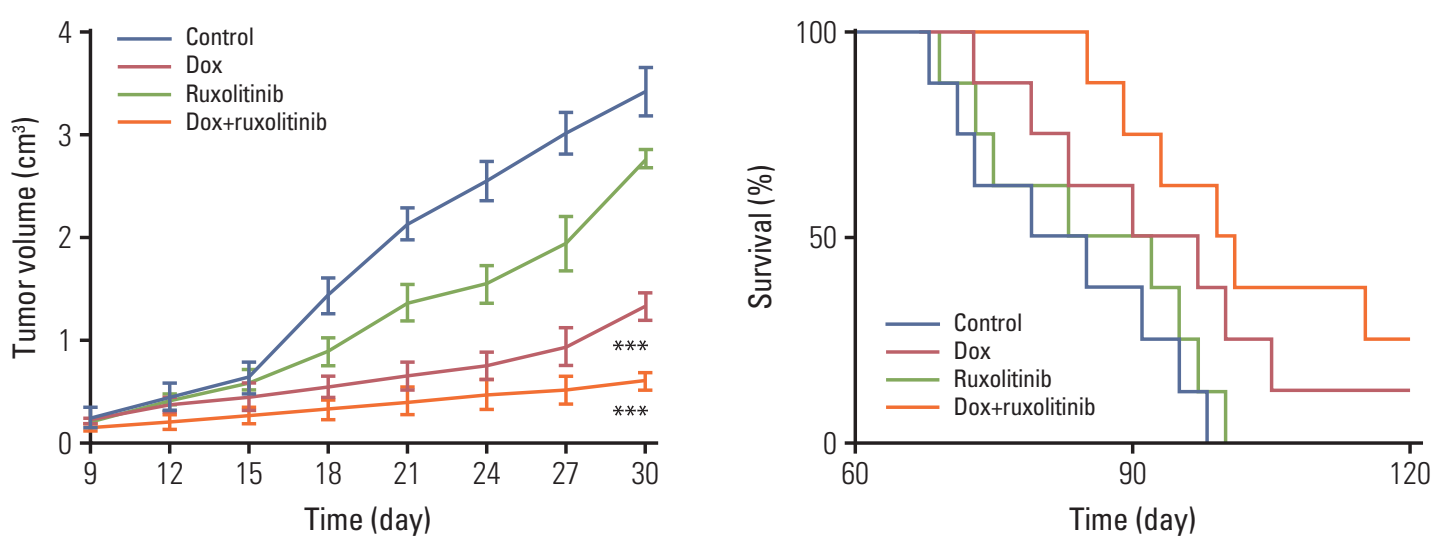

A
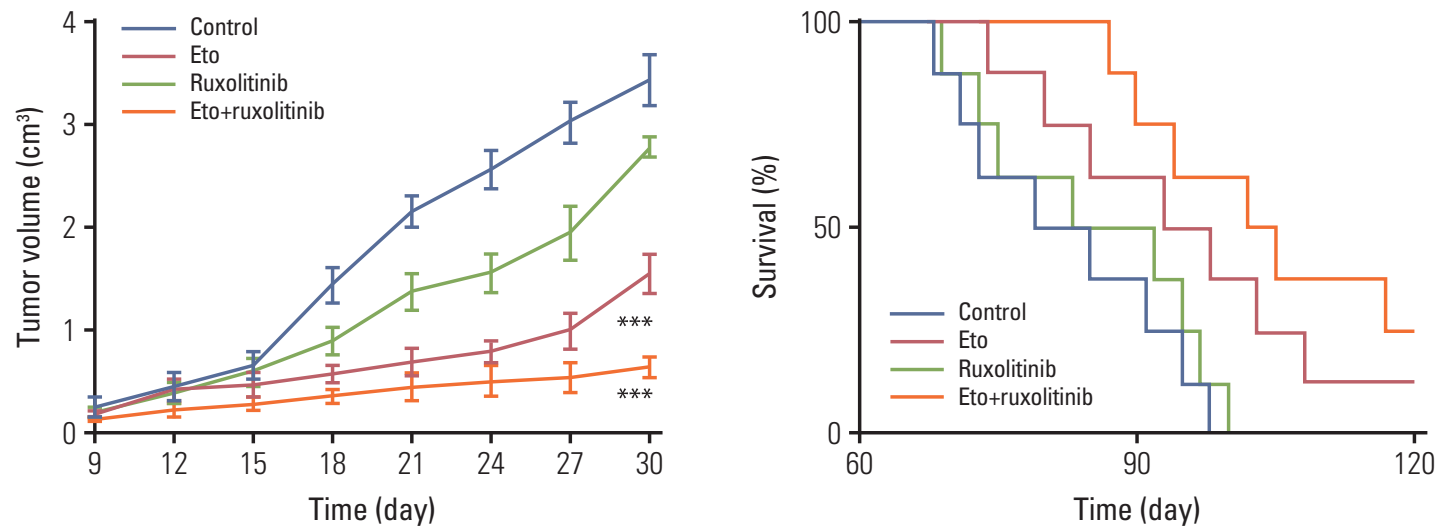

B
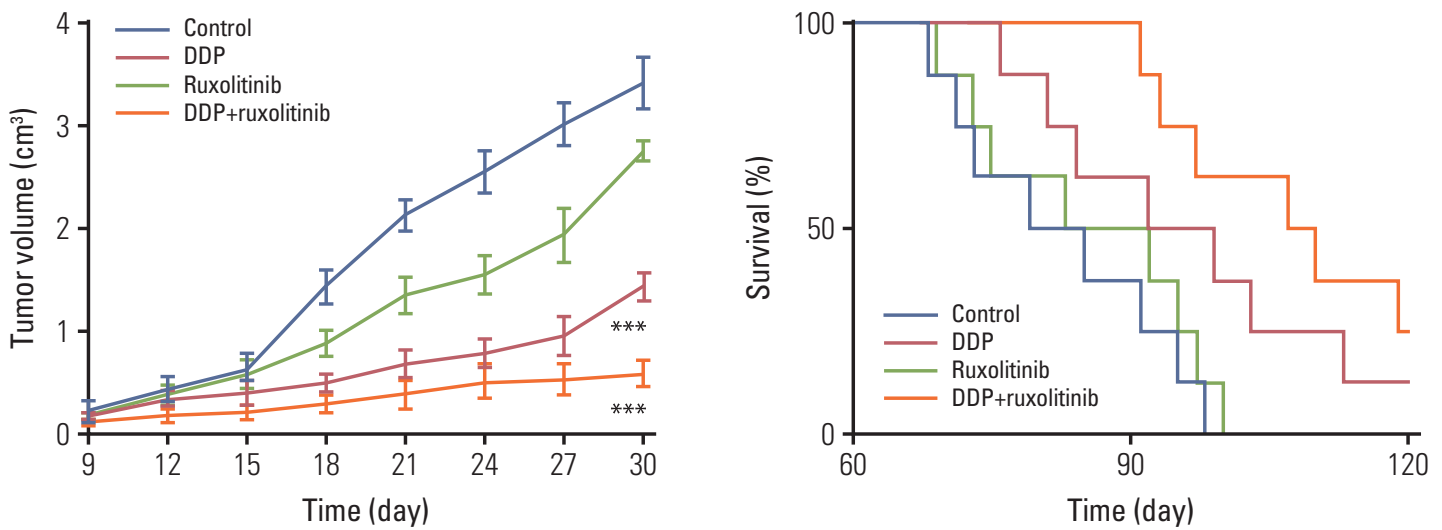

Fig. 5. Blockade interlukin (IL)-11/IL-11R signal relieves chemotherapy drug resistance in gastric cancer. (A) The mean tumor volume of NOD-SCID mice bearing SGC7901 cells implants in phosphate buffered saline (PBS), doxorubicin, ruxolitinib, or doxorubicin combing ruxolitinib (left); the long-term survival of tumor bearing mice treated with PBS, doxorubicin, ruxolitinib, or doxorubicin combing ruxolitinib (right). Eto, etoposide; Dox, doxorubicin. (B) The mean tumor volume of NOD-SCID mice bearing SGC7901 cells implants in PBS, etoposide, ruxolitinib, or etoposide combing ruxolitinib (left); the long-term survival of tumor bearing mice treated with PBS, etoposide, ruxolitinib, or etoposide combing ruxolitinib (right). (C) The mean tumor volume of NOD-SCID mice bearing SGC7901 cells implants in PBS, DDP, ruxolitinib, or DDP combing ruxolitinib (left); the long-term survival of tumor bearing mice treated with PBS, DDP, ruxolitinib, or DDP combing ruxolitinib (right). (Continued to the next page) 

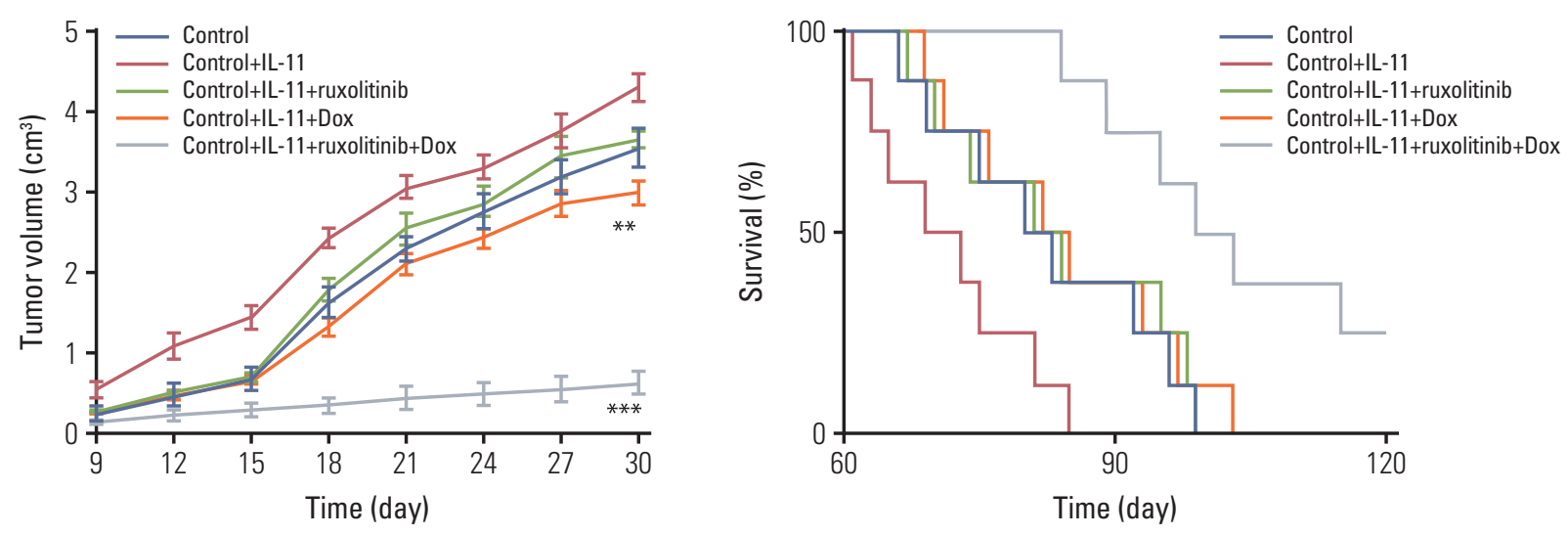

D
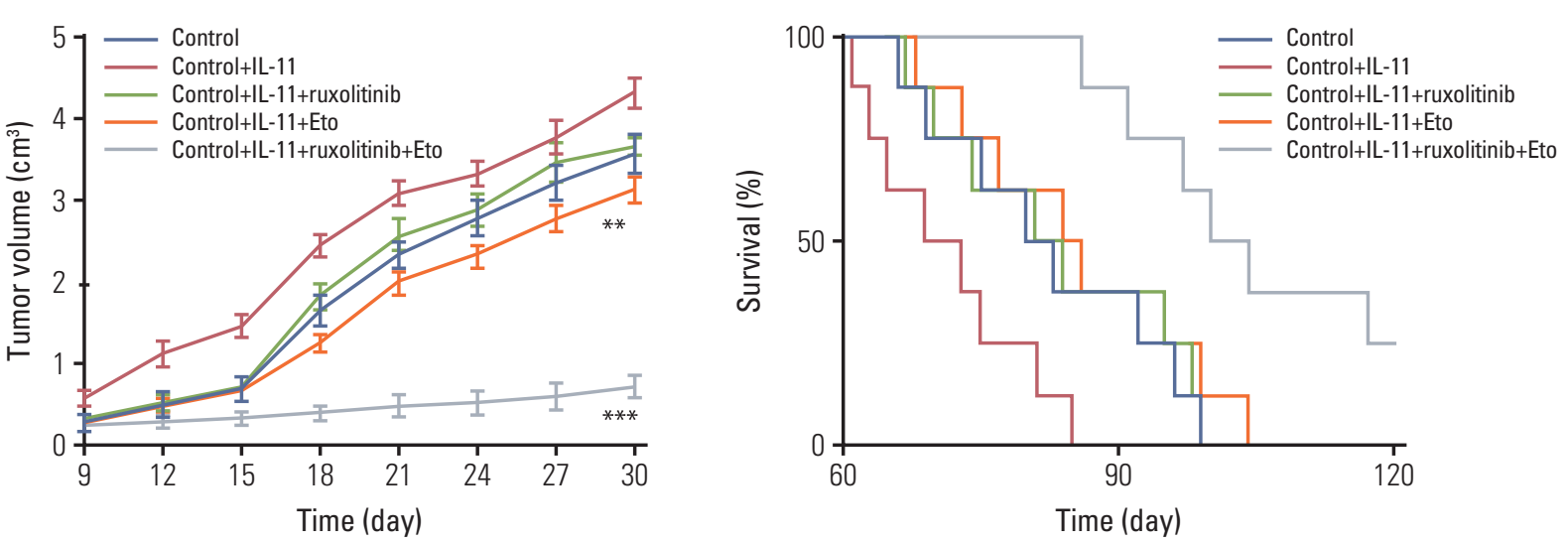

$\mathbf{E}$
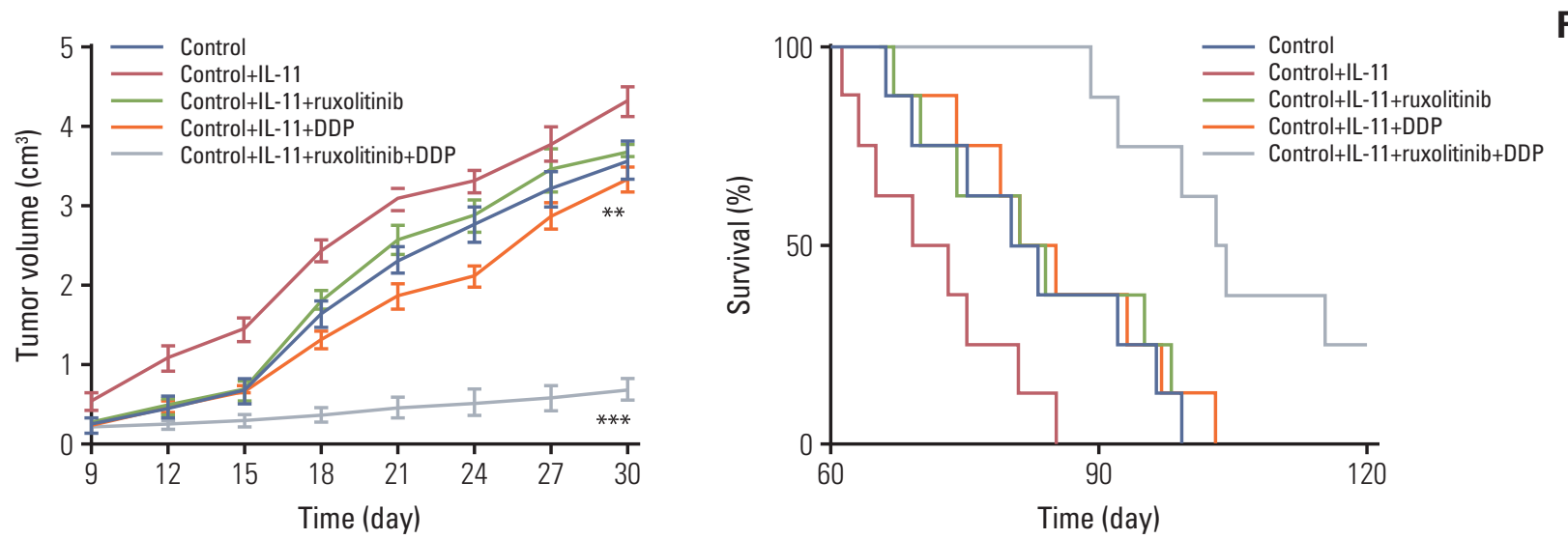

Fig. 5. (Continued from the previous page) (D) The mean tumor volume of NOD-SCID mice bearing SGC7901 cells injected with rhIL-11 and then treated with PBS, doxorubicin, ruxolitinib, or doxorubicin combing ruxolitinib (left); the long-term survival of NOD-SCID mice bearing SGC7901 cells injected with rhIL-11 $(2.5 \mu \mathrm{g} / \mathrm{kg})$ and then treated with PBS, doxorubicin, ruxolitinib, or doxorubicin combing ruxolitinib (right). (E) The mean tumor volume of NOD-SCID mice bearing SGC7901 cells injected with rhIL-11 $(2.5 \mu \mathrm{g} / \mathrm{kg})$ and then treated with PBS, etoposide, ruxolitinib, or etoposide combing ruxolitinib (left); the long-term survival of NOD-SCID mice bearing SGC7901 cells injected with rhIL-11 and then treated with PBS, etoposide, ruxolitinib, or etoposide combing ruxolitinib (right). (F) The mean tumor volume of NOD-SCID mice bearing SGC7901 cells injected with rhIL-11 $(2.5 \mu \mathrm{g} / \mathrm{kg})$ and then treated with PBS, DDP, ruxolitinib, or DDP combing ruxolitinib (left); the long-term survival of NOD-SCID mice bearing SGC7901 cells injected with rhIL-11 and then treated with PBS, DDP, ruxolitinib, or DDP combing ruxolitinib (right). (Continued to the next page) 


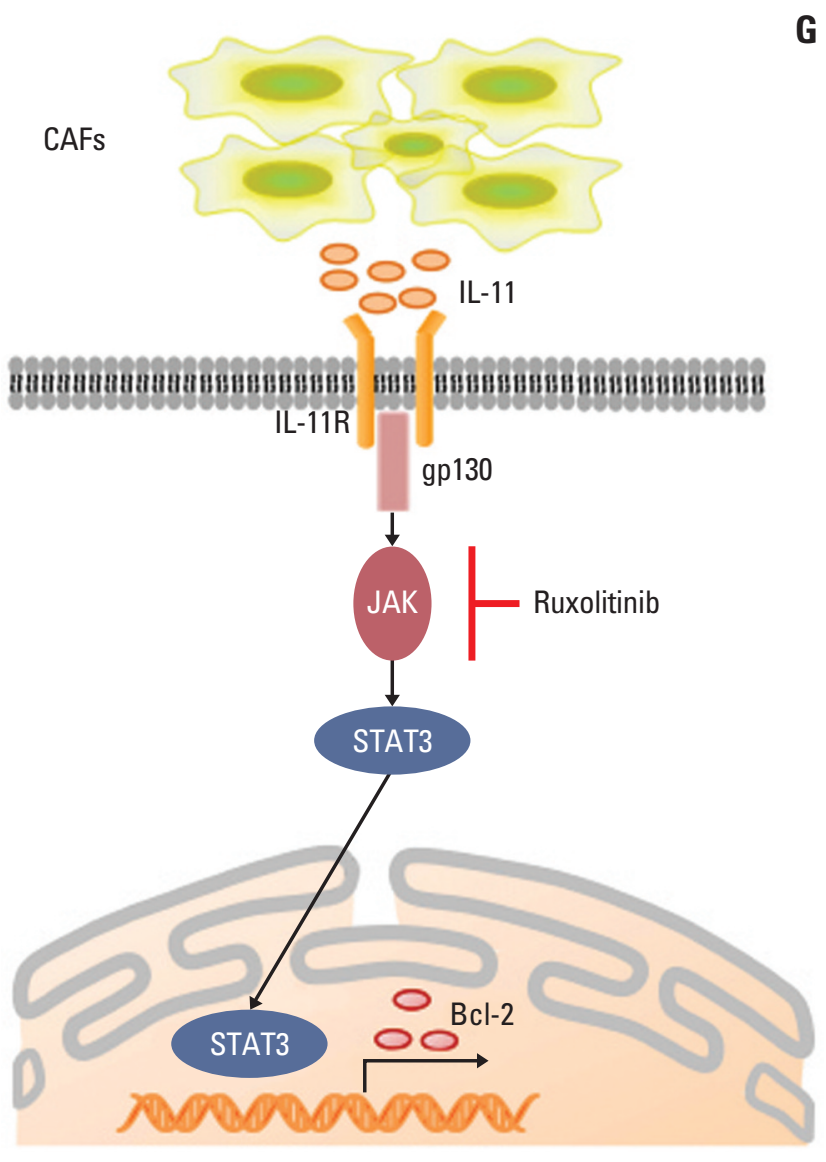

Fig. 5. (Continued from the previous page) $(G)$ The schematic diagram of drug resistance development induced by IL-11 in gastric cancer cells. The data was presented as the mean \pm standard error of mean from three independent experiments. ${ }^{* *} \mathrm{p}<0.01,{ }^{* * *} \mathrm{p}<0.001$.

rhIL-11 pre-treatment significantly enhanced the resistance of BGC823 and SGC7901 cells to DDP, doxorubicin and etoposide, while silencing Bcl2 effectively reversed the drug resistance (Fig. 4C and D). Together, these data suggested that Bcl2 may work as the downstream of IL-11/JAK/STAT3 pathway to participate in the process of acquiring drug resistance in gastric cancer.

\section{Blockade of IL-11/IL-11R signal relieves chemotherapy drug resistance in gastric cancer}

Next, we investigated the effect of IL-11 on JAK/STAT3/ $\mathrm{Bcl} 2$ pathway induced drug resistance in vivo. Here, we generated the mice models bearing SGC7901 cells model and treated with doxorubicin, ruxolitinib (JAK inhibitor) or the combination. We found that doxorubicin or ruxolitinib alone could slightly inhibit the tumor growth, while the combina- tion remarkably slowed the tumor growth (Fig. 5A, left). In consistent, combining doxorubicin with ruxolitinib significantly prolonged survival time compared to control group, while monotherapy had slight effect (Fig. 5A, right). Similarly, we found that DDP/etoposide or ruxolitinib alone could slightly inhibit the tumor growth, while the combination remarkably slowed the tumor growth (Fig. 5B and C, left). In consistent, combining DDP/etoposide with ruxolitinib significantly prolonged survival time compared to control group, while monotherapy had slight effect (Fig. 5B and C, right). These results suggested that blocking IL-11/JAK/ STAT3 pathway may be helpful to enhance the chemotherapeutic effect for gastric cancer.

Further, we generated the xenograft mouse bearing SGC7901 cells model. Then IL-11 was injected into the mice by intratumor injection. After four days, mice were treated with doxorubicin, ruxolitinib, or the combination. The IL-11 treated mice showed significantly resistant to the doxorubicin, while combining doxorubicin with ruxolitinib successfully slowed the tumor growth (Fig. 5D, left). In consistent, combining doxorubicin with ruxolitinib significantly prolonged survival time, while monotherapy had limited effect compared to control group (Fig. 5D, right). Similar results were achieved when treated NOD-SCID mice bearing SGC7901 cells model with DDP and Etoposide combined with or without ruxolitinib (Fig. 5E and F). These data suggested the potential therapeutic value of ruxolitinib combining with chemotherapy drugs in gastric cancer treatment.

\section{Discussion}

In our study, we found a subpopulation of CAFs existing in gastric cancer tissues, which play a crucial role in development of multi-drug resistance of gastric cancer. It has been reported that CAFs could participate in various tumor progress, including cancer stemness maintain, cancer metastasis, activation of pro-survival signaling pathway, and so on [25]. Here, we showed that CAFs facilitate the resistance of gastric cancer to multiple chemotherapeutic agents via secreting IL-11 and activation of IL-11/JAK/STAT3/Bcl2 signaling pathway. The IL-11 produced by CAFs activates the JAK signaling by binding to the membrane receptor IL-11R, leading to the GP130 expression. The activated GP130 triggered the phosphorylation of JAK, which then resulted in the activation of transcription factor STAT3. Then the phosphorylated STAT3 up-regulated the anti-apoptosis factor Bcl2 expression, resulting in the drug resistance development in gastric cancer (Fig. 5G).

A series of crucial factors are believed to be associated with 
the development of multi-drugs resistance in cancer, such as up-regulation of $\mathrm{ABC}$ transporters, DNA damages repair, rebalance of anti-apoptosis or pro-apoptosis regulators and various constituents in tumor microenvironment [26]. It has been demonstrated that the microenvironment could orchestrate the tumor progress by recruitment of inflammatory cells and secretion of pro-survival cytokines, leading to the promotion of tumor growth and drug resistance development [27]. However, traditional cancer therapy focuses on the inhibition of tumor cell proliferation but ignoring the tumor microenvironment elements [28]. Previous studies had attempts to reverse the drug resistance in cancer treatments, including the application of chemo-sensitizers [29], combination of several chemotherapeutic agents and so on [30], which was demonstrated to be capable of reversing the drug resistance and suppressing the tumor growth in early stage. However, recent studies indicated that the tumor microenvironment could induce the drug resistance in tumor tissues and the cancer cells could reacquire the drug resistance under appropriate microenvironment [31]. Herein, innovative strategy to target the tumor microenvironment is an urgent demand for the clinic cancer treatment.

CAFs, an important element in tumor microenvironment, have been demonstrated to secret various cytokines to participate in the tumor growth and metastasis [32]. However, the mechanisms of the CAFs induced tumor progressions are still remained to be unclear. Our studies firstly demonstrated that CAFs could facilitate the gastric cancer drug resistance development through the secretion of IL-11. A recent study showed that activation phosphoinositide 3-kinase signal is associated with the IL-11 induced the tumor growth enhancement [33]. And recent studies proved that IL-11 also serves as tumor-promoting cytokines in colon cancer through the activation of GP130 receptor [34]. Here, we revealed that the $\mathrm{Bcl} 2$ up-regulation in gastric cancer results in the drug resistance, which is induced by the activation of JAK/STAT3 signaling pathway. Furthermore, Ruxolitinib, a JAK signaling inhibitor, could serve as a potential agent to block the IL-11/ IL-11R paracrine pathway induced by CAFs and be combined with multiple chemotherapeutic agents to effectively reverse the drug resistance and inhibit gastric cancer progression.

In conclusion, our results described a novel role of CAFs and IL-11 in drug resistance of gastric cancer. Our findings validated that CAFs could regulate the drug resistance in a paracrine manner through IL-11/JAK/STAT3/BCL2 signaling pathway. And the combination of IL-11R inhibitor and chemotherapeutic agents might be explored as a potential strategy to gastric cancer therapy.

\section{Electronic Supplementary Material}

Supplementary materials are available at Cancer Research and Treatment website (https: //www.e-crt.org).

\section{Conflicts of Interest}

Conflict of interest relevant to this article was not reported.

\section{Acknowledgments}

This work was supported by grants from the natural science foundation of Zhejiang Province (LY15H160030, Y.P. Mou).

\section{References}

1. Chen W, Zheng R, Baade PD, Zhang S, Zeng H, Bray F, et al. Cancer statistics in China, 2015. CA Cancer J Clin. 2016;66:11532.

2. Holohan C, Van Schaeybroeck S, Longley DB, Johnston PG. Cancer drug resistance: an evolving paradigm. Nat Rev Cancer. 2013;13:714-26.

3. Juan TY, Roffler SR, Hou HS, Huang SM, Chen KC, Leu YL, et al. Antiangiogenesis targeting tumor microenvironment synergizes glucuronide prodrug antitumor activity. Clin Cancer Res. 2009;15:4600-11.

4. Quail DF, Joyce JA. Microenvironmental regulation of tumor progression and metastasis. Nat Med. 2013;19:1423-37.

5. Kikuchi K, McNamara KM, Miki Y, Moon JY, Choi MH, Omata F, et al. Effects of cytokines derived from cancer-associated fibroblasts on androgen synthetic enzymes in estrogen receptor-negative breast carcinoma. Breast Cancer Res Treat. 2017;166:709-23.

6. Chua AC, Klopcic BR, Ho DS, Fu SK, Forrest CH, Croft KD, et al. Dietary iron enhances colonic inflammation and IL-6/ IL-11-Stat3 signaling promoting colonic tumor development in mice. PLoS One. 2013;8:e78850.

7. Putoczki TL, Ernst M. IL-11 signaling as a therapeutic target for cancer. Immunotherapy. 2015;7:441-53.

8. Tao L, Huang G, Wang R, Pan Y, He Z, Chu X, et al. Cancerassociated fibroblasts treated with cisplatin facilitates chemoresistance of lung adenocarcinoma through IL-11/IL-11R/ STAT3 signaling pathway. Sci Rep. 2016;6:38408.

9. Johnstone CN, Chand A, Putoczki TL, Ernst M. Emerging roles for IL-11 signaling in cancer development and progression: focus on breast cancer. Cytokine Growth Factor Rev. 
2015;26:489-98.

10. Sanchez-Lopez E, Flashner-Abramson E, Shalapour S, Zhong Z, Taniguchi K, Levitzki A, et al. Targeting colorectal cancer via its microenvironment by inhibiting IGF-1 receptor-insulin receptor substrate and STAT3 signaling. Oncogene. 2016;35: 2634-44.

11. Zheng H, Yang Y, Han J, Jiang WH, Chen C, Wang MC, et al. TMED3 promotes hepatocellular carcinoma progression via IL-11/STAT3 signaling. Sci Rep. 2016;6:37070.

12. Hwang RF, Moore T, Arumugam T, Ramachandran V, Amos $\mathrm{KD}$, Rivera A, et al. Cancer-associated stromal fibroblasts promote pancreatic tumor progression. Cancer Res. 2008;68:91826.

13. Johnson P, Beswick EJ, Chao C, Powell DW, Hellmich MR, Pinchuk IV. Isolation of CD 90+ fibroblast/myofibroblasts from human frozen gastrointestinal specimens. J Vis Exp. 2016:e53691.

14. Johnston A, Xing X, Guzman AM, Riblett M, Loyd CM, Ward NL, et al. IL-1F5, -F6, -F8, and -F9: a novel IL-1 family signaling system that is active in psoriasis and promotes keratinocyte antimicrobial peptide expression. J Immunol. 2011;186:261322.

15. Varas-Godoy M, Rice G, Illanes SE. The crosstalk between ovarian cancer stem cell niche and the tumor microenvironment. Stem Cells Int. 2017;2017:5263974.

16. Danhier F, Feron O, Preat V. To exploit the tumor microenvironment: passive and active tumor targeting of nanocarriers for anti-cancer drug delivery. J Control Release. 2010;148:13546.

17. Paraiso KH, Smalley KS. Fibroblast-mediated drug resistance in cancer. Biochem Pharmacol. 2013;85:1033-41.

18. Flach EH, Rebecca VW, Herlyn M, Smalley KS, Anderson AR. Fibroblasts contribute to melanoma tumor growth and drug resistance. Mol Pharm. 2011;8:2039-49.

19. Cavaco A, Rezaei M, Niland S, Eble JA. Collateral damage intended-cancer-associated fibroblasts and vasculature are potential targets in cancer therapy. Int J Mol Sci. 2017;18:E2355.

20. Gal P, Varinska L, Faber L, Novak S, Szabo P, Mitrengova P, et al. How signaling molecules regulate tumor microenvironment: parallels to wound repair. Molecules. 2017;22:E1818.

21. Setrerrahmane S, Xu H. Tumor-related interleukins: old validated targets for new anti-cancer drug development. Mol Cancer. 2017;16:153.

22. Ren C, Chen Y, Han C, Fu D, Chen H. Plasma interleukin-11 (IL-11) levels have diagnostic and prognostic roles in patients with pancreatic cancer. Tumour Biol. 2014;35:11467-72.
23. De Araujo RF Jr, Pessoa JB, Cruz LJ, Chan AB, De Castro Miguel E, Cavalcante RS, et al. Apoptosis in human liver carcinoma caused by gold nanoparticles in combination with carvedilol is mediated via modulation of MAPK/Akt/mTOR pathway and EGFR/FAAD proteins. Int J Oncol. 2018;52:189200.

24. Guerriero L, Palmieri G, De Marco M, Cossu A, Remondelli P, Capunzo M, et al. The anti-apoptotic BAG3 protein is involved in BRAF inhibitor resistance in melanoma cells. Oncotarget. 2017;8:80393-404.

25. Turner N, Grose R. Fibroblast growth factor signalling: from development to cancer. Nat Rev Cancer. 2010;10:116-29.

26. Sun Y, Campisi J, Higano C, Beer TM, Porter P, Coleman I, et al. Treatment-induced damage to the tumor microenvironment promotes prostate cancer therapy resistance through WNT16B. Nat Med. 2012;18:1359-68.

27. Straussman R, Morikawa T, Shee K, Barzily-Rokni M, Qian $\mathrm{ZR}, \mathrm{Du} \mathrm{J}$, et al. Tumour micro-environment elicits innate resistance to RAF inhibitors through HGF secretion. Nature. 2012;487:500-4.

28. Baudino TA. Targeted cancer therapy: the next generation of cancer treatment. Curr Drug Discov Technol. 2015;12:3-20.

29. Coley HM. Overcoming multidrug resistance in cancer: clinical studies of p-glycoprotein inhibitors. Methods Mol Biol. 2010;596:341-58.

30. Zhu W, Li Y, Liu L, Chen Y, Xi F. Supramolecular hydrogels as a universal scaffold for stepwise delivering Dox and Dox/ cisplatin loaded block copolymer micelles. Int J Pharm. 2012; 437:11-9.

31. Meads MB, Gatenby RA, Dalton WS. Environment-mediated drug resistance: a major contributor to minimal residual disease. Nat Rev Cancer. 2009;9:665-74.

32. Yu Y, Xiao CH, Tan LD, Wang QS, Li XQ, Feng YM. Cancerassociated fibroblasts induce epithelial-mesenchymal transition of breast cancer cells through paracrine TGF-beta signalling. Br J Cancer. 2014;110:724-32.

33. Nakayama T, Yoshizaki A, Izumida S, Suehiro T, Miura S, Uemura T, et al. Expression of interleukin-11 (IL-11) and IL-11 receptor alpha in human gastric carcinoma and IL-11 upregulates the invasive activity of human gastric carcinoma cells. Int J Oncol. 2007;30:825-33.

34. Ernst M, Najdovska M, Grail D, Lundgren-May T, Buchert M, Tye $\mathrm{H}$, et al. STAT3 and STAT1 mediate IL-11-dependent and inflammation-associated gastric tumorigenesis in gp130 receptor mutant mice. J Clin Invest. 2008;118:1727-38. 